Istituto di Patologia Generale della $R$. Università di Bologna dirotto dal Prof. G. Tizzoni.

\title{
Experimentelle Untersuchungen über die Wirkung des Radiums auf das Hautgewebe.
}

Von

Dr. G. Guyot,

Assistenten.

(Hiezu Taf, V-VIII.)

Curie und Becquerel schreiben in ibrer Mitteilung an die Academie des Sciences (1901) Walk of f und Giesel die Priorität zu, die Wirkung des Radiums auf die Haut fast ein Jahr vor ihnen selbst (1900) untersucht $z u$ haben. Das Verdienst gebührt jedoch gewiß den zwei hervorragenden französischen Forschern, die Aufmerksamkeit der wissenschaftlichen Welt auf die geheimnisvollen Wirkungen gelenkt zu haben, welche das Radium auf den tierischen Körper hervorruft.

Wir sagen geheimnisvoll, weil wir, trotzdem eine große Zahl von Forschern sich damit betraut hat, die Art der Wirkung des Radiums auf die Zellen und Gewebe zu untersuchen, in Wirklichkeit nur sebr wenig Konkretes über die Frage wissen.

Beginnen wir von der aktiven Substanz, so wissen wir, es ist wahr, daß die $\alpha$-Strahlen als nicht beteiligt bei der Erzeugung der Gewebsveränderungen anzusehen sind, da sie ein so beschränktes Penetrationsrermögen haben, daß sie das Guttaperchahäntchen oder das Glimmerblättchen, das bei den gewöhnlichen Apparaten sich zwischen dem radioaktiven Präparate und dem Gewebe befindet, nicht zu passieren vermögen, es ist aber mit Bestimmtheit noch nicht entschieden, ob mehr den $\beta$ - oder den $\gamma$-Strahlen der Hauptanteil bei der Erzeugung der Gewebsveränderungen zukommt. Wegen der physikalischen Ähnlichkeit zwischen

1) Diese Arbeit bildet die Ergänzung einer Mitteilung, die im Zentralblatt für allgem. Pathologie und pathol. Anatomie, Bd. XX, Nr. 6, 1909, erschienen ist. 
den $\gamma$-Strahlen und Röntgenstrahlen und da man weil, daß die Röntgenstrahlen an den Geweben sehr ähnliche, wenn nicht gleiche Veränderungen wie das Radium hervorrufen, nimmt man an, daß auf die $\gamma$-Strahlen, die auch das größte Penetrationsvermögen besitzen, zum größten Teile die Wirkung, die man an den Geweben findet, zurückzuführen sind.

So ist auch der Wirkungsanteil der Bestrahlungen und der der Emanationen noch nicht festgestellt. Bei gewissen Versuchen muß man, da die Emanationen vollständig ausgeschlossen waren, die erzielten Wirkungen gänzlich auf die Strahlungen zurückführen, Wirkungen, die ganz identisch waren mit den bei gleichzeitiger Einwirkung der Strahlungen und der Emanationen gefundenen, So wird z. B. in dem klassischen Versuche von Bec querel, der sich eine typische Radiumdermatitis zuzog, als er in seiner Westentasche ein Muster sehr aktiven (800.000 Rad. Einheit.) Radiums, eingeschlossen in einer an beiden Enden geschlossenen Glasröhre trug, die Emanation vollständig ausgeschlossen. Dasselbe gilt bei allen anderen Versuchen, bei denen das Radium in einer Glasröhre eingeschlossen zur Anwendung kommt, welche die Emanation nicht passieren läßt

Dagegen fanden Danysz und Curie, die mit in Wasser gelösten Emanationen arbeiteten, bei denselben die gleiche Wirkung auf die Larven von Ephertia Kuehniella wie bei den Strahlungen. Aus den Versuchen von S c h a per geht andererseits hervor, daß die Emanationen auf die Froschlarven dieselbe Wirkung ausüben wie die Strahlungen. Auch Goldberg nimmt an, daß die Emanation und Strahlung anf die Haut wesentlich die gleiche Wirkung haben. Braunstein wies dann nach, daßs die Injektion radioaktiven Wassers in den Carcinomen deren Zerfall hervorruft, woraus er schließt, daß die primäre Veränderung der Zellen durch die Emanation bedingt wird.

Auch aus den Versuchen von Wirtrebert mit den Wässern von Plombiéres, welche in erheblicher Quantität radioaktive Emanation enthalten, geht hervor, daß dieselben Wässer einen bemerkenswerten Einfluß auf die Entwicklung und das Wachstum der Froschlarven ausüben. Kürzlich teilte auch Wichmann mit, positive Wirkungen auf die Hant durch die Emanationen erzielt zu haben.

Wir beabsichtigen hier von der direkten lokalen Wirkung zu sprechen, da auf internem Wege die Emanationen, jetzt nach einer großen Zahl von Forschern, einen deutlichen Einfluß auf den Stoffwechsel besitzen sollen.

Es ist wahrscheinlich, daß den Strahlungen und den Emanationen in gewisser Beziehung eine gemeinsame Wirkung zukommt, ebenso wie es wahrscheinlich ist, dab sie sich gegenseitig ergänzen und ihre Energie wirksam verstärken.

Interessant ist in dieser Hinsicht die von $\mathrm{Tizzoni}$ und $\mathrm{B}$ ongiovanni nachgewiesene Tatsache, daß die Strablungen, bei Abwesenheit der Emanationen, nicht im stande sind die induzierte Radioaktivität auf das Gehirn anszuüben. 
Bezüglich der Art, wie das Radium auf die Zellen und Gewebe wirkt, sind die Meinungen der verschiedenen Forscher auch heute noch sehr verschieden.

Über eine sehr wichtige Tatsache sind alle einig, darüber nämlich daß das Radium auf die Zellen eine solche Wirkung ausübt, welche nicht sofort, sondern ers $t$ nach einer gewissen Latenzzeit bemerkbar wird. Diese Tatsache wurde nicht nur bei den therapentischen Applikationen. des Radiums an der Haut und Tumoren konstatiert, sondern auch bei Experimenten an Eiern, Larven und Emboyonen. Interessant sind dies bezüglich die Versuche von Perthes, aus denen hervorgeht, daß bei bestrahlten Eiern die Initialteilung fast wie bei den normalen vor sich geht und daß das Wachstum erst nach den ersten Entwicklungsphasen Halt macht.

Werner beschäftigte sich in spezieller Weise mit dem Studium der Latenz bei den auf Radiumbestrahlung der Kaninchenhaut eintretenden Erscheinungen; er wies nach, dab die makroskopisch sichtbaren Veränderungen an der Haut später auftreten als deutliche mikroskopisch erkennbare Zellalterationen. W ern er zeigte ferner, daß die Latenz umgekehrt proportional der Dauer der Radiumapplikation und der radioaktiven Intensität ist. B e cqu erel selbst hatte schon gefunden, daß einer kürzeren. Bestrahlangsdauer eine längere Latenzperiode entspricht. Tatsächlich rief dieselbe Radiumröhre, die in einem Winkel der Westentasche sechs Stunden gehalten eine Radiodermatitis erzeugte, deren erste Zeichen nach etwa zwanzig Tagen auftraten, in einem anderen Winkel derselben Tasche nur eine Stunde gehalten, eine leichtcre Radiodermatitis hervor, die erst nach 34 Tagen zum Ausbruche kam.

Über die Ursachen der Lateuz wissen wir wenig, und die von den meisten angenommene Hypothese, daß das Radinm in dem vitalen Teile (im Kerne) der Zelle eine solche Veränderung erzeugt, die ganz allmählich eine Umwälzung des weiteren Wachstums und Stoffwechselprozesse der Zelle zur Folge hat, besagt auch nicht viel.

Eine andere, sicher festgestellte Tatsache ist die, daß das Radium die größte Wirkung auf solche Zellen oder Zellgruppen ausübt, deren Entwicklung wenig fortgeschritten ist und die sich im Zustand der Vermehrung oder Umwandlung befinden.

Bezüglich des Penetrationsvermögens des Radiums nimmt man mit Exner, Apolant, Werner, Hirschell, Blauel, Wichmannu. a. an, daß dasselbe relativ gering ist und $1 \mathrm{~cm}$ Gewebsdicke nicht überschreitet.

Die Veränderungen, die das Radium an denZellen und Geweben hervorruft, werden von der Mehrzahl der Autoren für reggressiver Natur gehalten. Hier finden wir in der Hauptsache die klinisehe Beobachtung in Übereinstimmung mit dem Laboratoriumsexperimente. Es wäre schwierig, einen vollständigen Überblick über die reichhaltige Kasuistik zu geben, die mitgeteilt wurde zur Illustration der zerstörenden Wirkung, die das Radium auf Tumoren und die verschiedensten pathologischen Prozesse speziell der Haut ausübt. Und wenn auch der großen Zahl im 
allgemeinen nicht eine glejche Vertiefung des Studiums entspricht, vielmehr die einfache makroskopische Beobachtung überwiegt, so haben wir doch eine gute Anzahl von Arbeiten, bei denen die rom Radium erzeugten regressiven Veränderungen auf Grund sorgfältiger wissenschaftlicher Untersuchungen beschrieben sind. Wir erinnern $u$. a. an die Arbeiten von Scholz, Halkin, Exner, Straßmann, Perthes, A polant, Werner, Werner und Hirschell, Braunstein, Rehns und Salomon, Einhorn, Blauel, Wickham, aus denen im ganzen hervorgeht, dab unter der Wirkung des Radiums die verschiedensten Krankheitsprozesse eine Involution erfuhren, die durch Volumenverminderung und totalem Schwund des pathologischen Gewebes charakterisjert ist.

An die auf klinisch-therapeutischem Gebiete gemachten Beobachtungen schlieben sich experimentelle, meist an der Haut angestelite Versuche an, u. a. die von Halkin, Scholz, Bohn, Goldberg, Danysz, Wichmann, Werner, Werner und Hirschel, an den Lidern von Tizzoni und Bongiovanni; an der Niere von Blauel, an den Hoden von Seholz und Thaler, an der Milz und den Lymphdrüsen von $\mathrm{Heinecke;} \mathrm{am} \mathrm{Zentralnervensysteme} \mathrm{von} \mathrm{Obersteiner}$, an den Muskeln und peripheren Nerven von Okoda, an den Muskeln, dem hyalinen Knorpel, Bindegewebe, der Leber, Milz, den Knochen, dem Knochenmarke, den Lymphdrüsen und Gefäßen von Thies. Aus allen diesen Untersuchungen geht ebenfalls im allgemeinen hervor, daß das Radium histolytische Veränderungen in den Geweben verursacht und, je nach der radioaktiven Intensität, die langsame Involution oder den Zerfall hervorruft.

Über den Verlauf des regressiven Prozesses wurden verschiedene, nicht immer übereinstimmende Erklärungen gegeben. Die von den verschiedenen Autoren beobachteten histologischen Veränderungen im bestrahlten Gewebe erwiesen sich nicht immer als identisch. Während z. B. Werner und Hirschel, Wichmann und andere bemerkten, daß die Reduktion der oberfächlichen Tumoren unter der Finwirkung des Radiums durch allmählichen Schwund der Geschwulstzellen und beim völligen Fehlen jeglicher sekundären Reaktion, sowohl im Gewebe als auch in der Umgebung vor sich gehe, beobachteten dagegen Halskin und $S \operatorname{tra} B$, daB die Zellatrophie der Tumoren von Endothelveränderungen an den kleinen Ernährungsgefäßen konkomittiert war und Exn er teilte sogar mit, daß der eigentlichen Atrophie eine entzündliche Reaktion des Bindegewebes voranging.

Aus dieser Ungleichheit der Beobachtung und der Interpretation ergab sich eine Hauptfrage, ob nämlich die Zellatrophie, die alle dem Radium zuschreiben, durch eine direkte Wirkung des Radiums auf die der Atrophie anheimfallenden Zellen zustande kommt oder ob sie sekundär durch andere Veränderungen hervorgerufen wird, die primär in der Umgebung des Tumors oder des bestrahlten Gewebes erzeugt wurden. 
Halkin und Scholz, die mit zuerst die Wirkung des Radiums auf die Gewebe untersuchten, erblickten in den frühzeitigen Endothelverändernngen der Gefäße den. Ausgangspunkt der Zellnekrobiose, die sie durch distrophische Wirkung als primäre auffaßten, indem sie der Infiltration des Stützgewebes die Bedeutung einer sekundären emtzündlichen Reaktion zuschrieben.

Auch Apolant schliebt sich jhnen an und nach den mit der Heilung von experimentellen Mänsecarcinomen erbaltenen Resultaten glaubt er, daß das Radium die Carcinomzellen primär schädigt, wenn gleich auch die Bindegewebsinfltration und die Gefäßschädigung beteiligt sein mögen. Goldberg ist der gleichen Ansicht und im groben ganzen auch $B l$ a uel, Wich man und andere.

Gegen diese Auffassung spricht die von Exner beschriebene Tatsache, daß acht Tage nacb geeigneter Bestrahlung von Hautcarcinomknötchen in denselben eine deutliche Bindegewebsneubildung beobachtet wurde, während an den wirklichen Carcinomzellen noch keine nennenswerten Veränderungen nachzuweisen waren; solche traten nur einige Tage später auf unter dem Bilde einer Vakualisation und Chromatolyse. Exner neigt daher zu der Annahme, daß infolge der Bestrahlung das physiologische Wachstumsgleichgewicht zwischen Bindegewebs- und Carcinomszellen in der Weise gestört wird, daß die Proliferationsaktivität des Bindegewebes die des Carcinoms übersteigt.

Was die Gefäße anbelangt, so stehen gegen die Meinung derjenigen, die als erste die Gefäßerkrankung annehmen und in dieser die Ursache der regressiven Zellveränderungen erblicken die Erfahrungen jener, welche den regressiven Prozeß ohne jegliche Gefäßveränderungen beobachteten.

Demjenigen, der den Ferlauf des Involutionsprozesses in den Geweben studieren wollte, ergaben sich deutlich große Schwierigkeiten bei der Verfolgung der regressiven Zellveränderungen in den differenzierten und komplizierten Geweben. Man dachte daher daran, für das Experiment einen einfacheren Weg zu wählen, um festzustellen, ob das Radium einen direkten Einfluß auf die Vitalität der Zellen in der Weise ausübt, daß es eine Störung in der biologischen Involution oder direkt den Tod hervorruft; diese Versuche stellte man an isolierten Zellen des Organismus (Eiern) und an elementaren Zellaggregaten (Embryonen und Larven) an.

Perthes untersuchte die Wirkung des Radiums auf die Eier von Ascaris megalocaephala und wies nach, daB das Radium eine Verzögerung der Zellteilungsprozesse und eine Unregelmäßigkeit in der Entwicklung bewirkt, die zur Entstehung von Mißbildungen führt.

Bohn beobachtete, daß das Radium die Entwicklungsphasen der Eier von Strongylocentrotus lividus stört und zum Stehen bringt. Außerdem fand er, daß die Spermatozoen durch das Radium rasch getötet werden. Bohn fand ferner noch bei Versuchen an Larven von $B$ ufo vulgaris und an Froschlarven, dab das Radium bei den 
ersten eine Verzögerung des Wachstums, bei den zweiten Verzögerung und Entstehung von Mißbildung bewirkt.

Schaper untersuchte die Wirkung des Radiums auf die Eier und Larven des Frosches und fand, gleich Perthes und Bohn, Entwicklungshemmungen und Entstehungen von Monstruositäten.

Danys zeobachtete, daß die Larven von Ephertia Kuehniella gelähmt wurden und starben.

$\mathrm{Zu}$ diesen Versuchen kommen jene, die an niederen einzelligen Organismen wie Protozöen und Amoeben ausgeführt wurden und jene noch an Bakterien. Auch auf diese einzelligen Organismen wirkt das Radium konstant deletär.

Es ist alles zur Genüge nachgewiesen, daß das Radium direkt die Vitalität der Zellen angreifen und dadurch regressive Prozesse in den Geweben hervorrufen kann.

Während aber über den finalen Ausgang des Prozesses ein $Z$ weifel nicht mehr besteht, erwarten die Phasen, um durch den regressiven Prozeß zur Zellatrophie zu gelangen, ihre Klärung.

Gegenüber den Tatsachen, welche die von dem Radium an den lebenden Elementen hervorgerufenen regressiven Veränderungen beweisen, dürfen jedoch andere Daten nicht übergangen werden, die zeigen würden, daß das Radium geradezu eine fundamentale entgegengesetzte Wirkung, nämlich eine solche regressiver Natur auszuüben vermag.

Aus den Untersuchungen von Bohn z. B. ergibt sich, daß das Radium, während es die Spermatozoën tötet, die proliferative Aktivität der Seeigeleieier zu steigen scheint. Tatsächlich erreichten nahezu abgestorbene Eier, die befruchtet kaum bis zur Zweiteilung zu gelangen vermochten, unter der Einwirkung des Radiums, wenn auch unregelmäßig, das Stadium der Vier- und Achtteilung. Außerdem wies B oh n nach, daß unbefruchtete Eier unter der Wirkung der Radiumstrahlen zum Teil (2-4\%) fähig werden, sich ohne Befruchtung partho genetisch zu entwickeln und unregelmäßige Embryonen zu erzeugen.

Wintrebert fand, daß die radioaktiven Wässer von $\mathrm{Plom}$ biéres die Entwicklung der Froschlarven begünstigen und die Metamorphosen begünstigen.

Veneziani sah, daß Exemplare von Opalina ranarum, in hängenden Tropfen von physiologischer Kochsalzlösung der Radium wirkung ausgesetzt, länger als die betreffenden Kontrolle leben.

Zuelzer stellte seine Experimente an Protozoen an und fand, daß die dem Radium ansgesetzte Delonysea palustris sich zuerst lebhaft bewegt, und daß die Strömung des Plasma beschleunigt ist. Dieselbe verlangsamt sich später und hört mit dem Ende des Lebens vollständig auf.

Dany $s$ konstatierte, daß die Wirkungen einer und derselben Bestrahlung auf die Meerschweinchen und Kaninchenhaut verschieden sind, indem beim Meersehweinchen Zerstörungsprozesse auftreten, während 
man beim Kaninchen eine stärkere Entwicklung der Behaarung, wahrscheinlich infolge eines Wachstamreizes, beobachtet.

Thies sah bei den Versuchen an der Haut eine Proliferation der Epidermiszellen und Bildung ron Zellnestern.

Matsuoka behauptet in einer neueren Arbeit, daß das Radium einerseits destruktiv, andererseits produktiv wirkt.

Werner nimmt an, dab gewisse Strahlungen wie ein traumatischer Reiz auf das Wachstum der Zellen wirken.

Wi ckham schreibt dem. Radium das Vermögen zu, die Zellen einfach zu verändern, sie in das embryonale Stadium zurückzubringen ohne dieselben zu zerstören und sie in der Tiefe der Gewebe herauszusuchen.

Wegen des Parallelismus, der zwischen der Wirkung der Röntgenstrahlen und der der Radiumstrahlen (Perthes, Heinecke usw. besteht, sind die Beobachtungen von Gilman und Ba etyer nennenswert, die unter der Wirkung der Röntgenstrahlen eine anfängliche Beschleunigung in der Entwicklung von Amphibien und Hühnerembryonen feststellten.

Übrigens wenn wir in das Gebiet der Anwendung des Radiums auf pathologische Gewebe eintreten, so haben wir die Beobachtungen von R. Werner und G. Hirschell, die bei der Behandlung von Pigmentierungen fanden, daß, wenn die Bestrablung schwach ist, statt einer Verminderung eine Vermebrung in der Pigmentproduktion eintritt, was nach Werner und Hirschell beweisen würde, daß eine unzureichende Bestrahlung statt eine Neubildung zu zerstören, vielmehr sie reize; sie glaubten aus einigen Fällen schließen zu können, daß Knötchen maligner Tumoren, die der Zerstörung entgangen sind, gereizt werden und der Ausgangspunkt von rasch verlaufenden, verhängnisvollen Rezidiven werden können.

Jn diesem Sinne würden auch einige Beobachtungen sprechen, die Engelken bei der Behandlung maligner Tumoren zu machen Gelegenheit hatte.

Wir haben die Experimente von Gilman und Baetyer mit den Röntgenstrahlen wegen der Analogie dieser Strahlen mit den $\gamma$ Radiumstrahlen erwähnt. Wegen derselben Analogie können wir noch daran erinnern, dal in der Literatur bereits mehrere Beobachtungen von Neubildungen (Keratome, Cancroide, Epitheliome) mitgeteilt sind, welche sich in der Haut von Individuen entwickelten, die durch ihre Profession häufig den Röntgenstrahlen ausgesetzt sind.

In neuerster Zeit wird in A me rika und England in spezieller Weise die Aufmerksamkeit der wissenschaftlichen Welt auf diese professionellen Neoplasien gelenkt.

Die Kasuistischen Mitteilungen von Porter und $W$ hite, Dean, Castiglioui behandeln diese wissenschaftlich aktuelle Frage.

Es scheint daher, da $B$ man beim Studium der Wirkungen, welche die radioaktive Energie auf die lebenden Elemente entfaltet, diese andere 
Fähigkeit des Radiums, nämlich die Zelltätigkeit zu reizen, nicht übersehen darf. Und es wird sicher von großem Interesse sein, in Zukunft festzustellen, wie ein physikalisches, für uns $z \mathfrak{u}$ geheimnisvolles Agens Wirkungen auszuüben vermag, die in unseren Augen in Antagonismus stehen.

Vielleicht wird man bei vertieftem Studium weiter an der Erkenntnis des intimen Mechanismus, der den biochemischen Veränderungen der Zellen unter der Einwirkung des Radiums zu Grunde liegt, gelangen, als es bis jetzt der Fall ist. Diesbezüglich haben bisher die Autoren meist nur vage Hypothesen aufgestellt. Eine einzige Theorie erweckte für einen Augenblick ein gewisses Interesse und schien auch einige Forscher auf diesem Gebiete zu befriedigen; es war die auf dem Verschwinden des Lecithins basierte Theorie von $\mathrm{Schwarz}$. G. S chwarz glaubte, ausgehend von der Beobachtung der Tatsache, daß die durch das Radium hervorgerufenen Veränderungen nicht sogleich, sondern erst nach einer gewissen Latenzperiode manifest werden, annehmen zu müssen, daß das Radium in den Gewebselementen eine Veränderung in der molekularen Anordnung bewirkt, die eine tief gehende Störung in der Struktur und der normalen Involution der Zellen zur Folge hat.

G. S chwarz hatte beobachtet, daß der Wirkung des Radiums ausgesetzte Hühnereier tiefgehende Veränderungen in der Farbe, Konsistenz und dem Geruche erfahren und daß diese Veränderungen in spezieller Weise den Dotter betreffen, während das Eiweiß sich nur ziemlich verdickt. $\mathrm{S}$ chwarz glaubte damals feststellen zu können, daß das Lecithin des Dotters besonders angegriffen wird und dab hauptsächlich auf der Zersetzung des Licithins die von den Be cquerel-Strahlen am Dotter hervorgerufenen Veränderungen beruhten.

Aber Lecithin enthalten in größerer oder geringerer Menge alle Zellen des animalen Organismus und besonders reich sind die gegenüber dem Radium empfindlichsten Zellen, wie die Eier, Embryonalzellen, Zellen der Epithelgewebe, die der schnell wachsenden Geschwülste und die nervösen Elemente. Infolgedessen muß man wach Schwarz annehmen, daß die vom Radium an den empfindlichen Geweben ausgeübten Veränderungen auf der Zersetzung des Zelllecithins beruhen.

Diese Hypothese, und wir sagen Hypothese, weil $\mathrm{Sch}$ warz selbst keinen Beweis für sie mit der chemischen Analyse lieferte, wurde günstig aufgenommen, $u$. a. von Schaper, und fand einen eifrigen Verfechter in $W$ erner.

Gegen dieselbe wurden aber wichtige Einwände von Wohlgemut und Neuberg gemacht.

Wohlgemut bemerkte, daß das Lecithin, wenn man es vor anderen zersetzenden Einflüssen schützt und so der Wirkung des Radiums anssetzt, keinerlei Veränderungen erleidet, auch wenn die Betrachtung lange ausgedehnt wird.

$\mathrm{N}$ eu berg zeigte dann, dab das Radium nur auf lebendes niemals aber auf totes oder gekochtes Gewebe einwirkt und dab nur im lebenden 
eime Zersetzung der Allumincolde eintritt. Deshalb schließt er aus, daß das Lecithin primär vom Radium beeinflußt wird und glaubt, daß die regressiven Prozesse, die in den bestrahlten Geweben auftreten, der Ausdruck eines fermentativen Prozesses sind, dem das Lecithin wie die anderen Zellkomponenten entgegengeht. Nach Neuberg soll das Radium das Vermögen haben, die natürliche Widerstandsfähigkeit abauschwächen oder za lähmen, welche die lebenden Gewebe der Wirkung der allen Zellen zukommenden, in den zum natürlichen Zerfall neigenden Geweben (Tumoren) sebr aktiven antolytischen Fermenten entgegensefzen. Die den Zellstoffwechsel begünstigenden Fermente werden dureh das Radium zerstört und überlassen das Feld den autolytischen Fermenten, welche einen rapiden Zerfall der Zellen bewirken.

Werner wies seinerseits, während er die Beobachtung von Wohlg em $\mathrm{u}$ bestätigte, jedoch darauf hin, daß das bestrahlte Licithin einer rascheren Zersetzung entgegengeht und daß eine relativ kurze Bestrahlung genügt, um die Zersełzlichkeit des Lecithins mittels der Teilungsund Zersetzungsprodukte $z \mathfrak{a}$ steigern, welche die Zellprotoplasmas intoxizieren, wenn auch zum Tode derselben der beobachtete Mangel des im Zellstoffwechsel so wichtigen Lipoides nicht beiträgt. Außerdem modifizierte er die Fermenttheorie in einer seine Anschauungen stützenden Weise ab, indem er annahm, daß, falls die antolytischen Fermente in der behaupteten Weise wirken, das Lecithin davon zuerst berührt wird und durch seine rapide Zersetzung den Zerfall der Gewebe hervorruft oder wenigstens begünstigt.

Die Theorie der Zersetzung des Lecithins und ihrer Wirkung auf die Gewebe erschien Werner eine Zeit lang so ansprechend and überzeugend, daß er die Zweckmäßigkeit des Ersatzes der Radium- und Röntgenstrahlen durch aktiviertes Lecithin ventilierte und das radioaktivierte Lecithin als einen Akkumulator der radioaktiven Energie bezeichnete.

Soviel uns bekannt ist, hat bis jetzt die Annahme von Werner keine nützliche Verwendung in der Praxis gefunden. So ist die Frage auch biochemisch wenig fortgeschritten und bleibt auf dem Gebiete der Hypothese beschränkt.

Aus diesen kurzen Literaturangaben glauben wir hervorheben zu können, daß unsere jetzigen Kenntnisse über die Wirkung des Radiums auf die Zellen und Gewebe noch nicht ganz sichergestellt sind, denn sie stützen sich auf nicht immer übereinstimmende, manchmal kontradiktoris che Versuche. Es ist nicht übertrieben, wenn man die Anwendung des Radiums, die bis jetzt in der Therapie versucht wurde, als empirisch zu betrachten, trotzdem versprechende Resultate erzielt wurden, dena die Anwendung des Radiums kann keine rationelle sein, so lange die physiologische Wirkung des Radiums selbst nicht festgestellt ist.

In einer so aktuellen und wichtigen Frage, in welcher sich wissenschaftliches und praktisches Interessse vereinigen und neve Studien und 
neue Forschungen erfordern, glaubten wir einen bescheidenen Beitrag zu liefern.

Als Ziel unserer Arbeit nahmen wir auf Anraten unseres Lehrers Prof. Tizzoni die fundamentale Frage an, nämlich diejenige, die sich auf die biomorphologischen Veränderungen der bestrahlten Gewebe bezieht; dábei wurden wir von der Absicht geleitet, nicht einen neuen Weg einzuschlagen, sondern unsere Beobachtungen auf alle Besonderheiten des physiopathologischen Prozesses zu fixieren, um die histologischen Grundlagen zu klären, auf denen die vom Radium hervorgerufenen anatomischen Veränderungen vor sich gehen.

\section{Experimentelle Untersuchungen.}

Die Wirkuug des Radiums wird am besten an gesunden Geweben versucht, denn in denselben finden wir einen sicheren Ausgangspunkt, um den Vorgang der Veränderungen verfolgen zu können.

Den gesunden Geweben widmeten wir somit unsere Versuche und dazu wählten wir, wie es schon mehrere Autoren taten, die Haut, nicht nur, weil sie das häufigste Anwendungsgebiet in der praktischen Radiotherapie darstellt, sondern vor allem auch, weil man an ihr mit dem Radium in idealer Weise experimentieren kann, d. i. unter Ausschluß operativer lingriffe, die direkt oder indirekt den Verlauf der vom Radium bedingten Veränderungen beeinflussen und die Resultate verdunkeln können.

Wir haben uns der Haut kleiner 'Tiere wegen des Vorteiles bedient, der darin liegt, daß die dünne Haut derselben in geringer Dicke verschiedenste Gewebe (Epithel und Derivate desselben, Bindegewebe, Muskein und Gefäbe) darbietet, die der Wirkung des Radiums zugänglich sind.

Diesen Vorteil bietet im höchsten Grade die Haut der Maus, welche mit ihrer Dünnheit eine relative Einfachheit der Zusammensetzung und eine große Empfindlichkeit gegenüber der Bestrahlung verbindet.

Aus diesem Grunde stellten wir unsere Versuche essentiell an der Haut der Maus an.

In zweiter Linie und nur wenn es interessant war, die Reaktion der Haut anderer Versuchstiere im Vergleiche zu jener der Maus kom. parativ zu kennen, haben wir unsere Versuche auch auf Meerschweinchen und Kaninchen ausgedehnt. Wir haben auch Untersuchungen an der gesunden Haut des Menschen begonnen, aber diese bleiben bis jetzt, wegen der Schwierigkeit Experimentmaterial zu haben, beschränkt.

Wir wollen hier in besonderer Weise die Resultate unserer Experimente an der Haut der Maus auseinandersetzen.

Unsere Versuche beziehen sich einerseits auf die Veränderungen, welche das Radium in den verschiedenen Bestandteilen der Haut hervor- 
ruft, andererseits auf die Art und Prozesse, durch die die vom Radium bedingten Veränderungen repariert werden.

\section{Teohnik und Anordung der Experimente.}

Bei unseren Experimenten haben wir uns immer einer Menge von 10 Centigramm Bromradium ま 1.500 .000 R. E. per zentigramm bedient; dasselbe hatte also eine Kapazität von 5.000.000 R. E. und war in einer Schachtel mit einem dünnen Glimmerblättchen; die strahlende Fläche urnfaßte $1 \mathrm{~cm}^{2}$; das ganze war ia einer Metallschachtel nach englischem Muster - der Firma Armet de Lisle a Nogent sur Marne - montiert.

Für die Bestrahlung der Tiere gebrauchte man eine innen mit Blei ausgekleidete, mit einem Scharnierdeckel versehene Holzschachtel; der Deckel war auch ausgekleidet; in der Mitte trug er eine Öfnung zur Anbringung der Radiumkapsel; die strahlende Oberfläche gegen das Innere der Schachtel gewendet, war von der nuteren Fiäche des Deckels einige Milimeter $(4-5)$ entfernt, an einer Stelle von einem metallischen Netze verstärkt, um den Apparat selbst zu schützeu und zu regeln ${ }^{1}$ ).

Die Schachtel war so, daß das Tier sich kaum bewegen konnte und bei seinen Bewegungen der Bestrahlung stets die gleiche Hautstelle am Forderen l'eile des Rückens dargeboten wurde. Die dem Radium direkt ausgesetzte Haut lag stets in einer Entfernung von zirka $1 \frac{1}{2}-2 \mathrm{~cm}$ von der strahlenden Fläche. Da die Schachtel geschlossen und mit Blei ausgekleidet war, so wurden die Emanationen und die Strahlungen von den Wänden der Schachtel selbst abgehalten.

Die gewählten Tiere waren junge und erwachsene (4-6 Monate alte) weile Mäuse - Mus decumanus.

Dieselben wurden beständig während der ganzen Zeit der Bestrahlung in der Schachtel gelassen und dort entsprechend genährt.

Die Bestrahlung dauerte gewöhnlich 48 Stunden; nur ausnahmsweise wurden 2 Mäuse 24 Stunden allein bestrahlt, um die Effekte einer kürzeren Bestrahlung sehen zu können.

Nach der Bestrablung wurden die entsprechend kontrasignierten Tiere in separierte Käfige gelegt und spezielle Protokolle aufgenommen.

Von den 18 bestrahlten Mäusen, davon 16 in der Dauer von 48 Stunden, starben 2 in der Beobachtungszeit; die anderen wurden in verschiedenen Abständen, 3-330 Tagen, getötet, und zwar 3, 5, 10, 14, 19, $20,26,37,45,70,71,95,120,150,180$ and 330 Tage nach der Bestrahlung ${ }^{2}$ ) (T. n. B.).

Nachdem das Tier getötet war, wurde jenes Stück Haut abgezogen, das infolge der sichtbaren Veränderungen am meisten der Wirkung des

1) Diese Anordnung ist dieselbe, welche in unserem Institute für gleiche Versuche angewendet wurde.

$\left.{ }^{2}\right)$ Der Kürze wegen werden wir in Folge durch T. n. B. deu Ausdruck "Tage nach der Bestrahlung" bezeichnen. 
Radiums ausgesetzt gewesen zu sein schien. Die Haut wurde in ihrer ganzen Dicke bis zur Subcutis, inbegriffen die Haare, exzidiert.

Das Hautstückchen wurde dann in verschiedene Stückchen geteilt, diese dann fixiert und zwar in Müllerscher Flüssigkeit (Müller-Formol, Zenker).

Nach der Fixierung wurden die Präparate in Paraffin eingebettet. Die Schnitte wurden nach den gewöhnlichen Methoden tingiert.

Allgemeiner Zustand und makroskopische Veränderungen nach der Bestrahlung.

Die Experimenttiere vertrugen die Bestrahlung ohne jegliche Störung des Allgemeinbefindens; ans dem Käfig genommen war ihr Befinden während ihrer ganzen Lebensdauer ein gutes; ihr Gewicht nahm regelmäßig zu. Eine Maus gebärte gesunde und lebensfähige Jungen, bei zwei Mäusen schritt die Schwangerschaft regelmäßig fort.

Nur zwei Tiere starben, respektive nach 37 und 71 Tagen. Die Autopsie ergab beim ersten starke Abmagerung und Pneumonieherde, beim zweiten nur Kachexie ohne nennenswerte Veränderungen in den Eingeweiden.

Die übrigen wurden in absteigender Reihe getötet.

Die nachfolgende Tabelle gibt mit der Beobachtungszeit die Zahl der untersuchten Mäuse wieder, sie dient dazu, um das Material anzugeben, an welchem wir bezüglich der bestrahlten Haut unsere makroskopische Untersuchung anstellten.

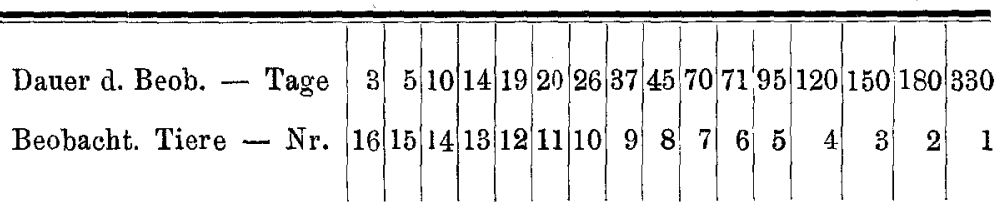

In den ersten vier oder fünf Tagen nach dem Beginne der Bestrablung bemerkt man mit dem bloßen Auge an der bestrablten Haut keine nennenswerten Veränderungen.

Gegen das Ende der ersten Woche finden wir die ersten Spuren. Bei der genauen Untersuchung der bestrahiten Partie fand man die Haare reichlicher. Zwischen denselben war die Oberfläche derselben von blasserer Farbe als normal; sie war weniger regelmäßig wegen kleiner emporragender, seborrhoeartiger Schuppen.

Die Schuppen vermehrten sich in den folgenden Tagen und trennten sich in kleine Partikelchen. Während der zweiten Woche vervollständigte der aktive Desquamationsprozeß der Epidermis, der von einer Verdickung der Cutis, ersichtlich durch die Größe der Falten, begleitet war. Mit den Epidermisschuppen fielen spontan einige Haare aus. 
Die adhärenten lassen sich bei der geringsten Traktion ausreißen zusammen mit Schuppen, die sich an ihrer Wurzel als Blättchen lagern. Zu Beginn der dritten Woche war der Haarausfall auBes: durch die Alopecie auch dadurch deatlich, daß das Haar minder homogen und verschieden gebogen erschien. Die Alopecie stellte sich gewöhnlich zwischen dem 15. und 20. Tage ein.

Den Haarausfall konkomittierte ein lebhafter phlogistischer ProzeB, der an der Hautoberfläche seinen Ausdruck fand. Zuerst präsentierte sich die durch den Ausfall der Haare und der seborrhoischen Schuppen entblößte Haut merklich gerötet. Hie und da waren Tropfen von Serum, die eintrocknend sich in gelbliche Krusten umwandelten, zwischen denen sich die übrigen Haare fanden.

Mit dem Serum mischte sich bald Blut und die Krusten wurden blutig. Zuerst war die Exsudation in Form von kleinen Herden; diese konfluierten bald und es entstand eine einzige, meistens ovale oder parallel der longituvinalen Achse des Körpers oblungierte Borke; ihre Extension war eine verschiedene von $2-4 \mathrm{~cm}$ Länge and $1-2 \mathrm{~cm}$ Breite. Sie lag gewöhnlich am vorderen Drittel des Dorsums und breitete sich bald nach hinten bis zur Mitte des Rückens selbst, bald nach vorne längs des Halses und Nackens aus, sogar den Kopfscheitel erreichend.

Die Borke verdickte sich in den folgenden Tagen nach ihrer Bildung und wurde hart; rundherum fielen einige Haare aus, die sich von breiten Epidermisschuppen trennten. In dieser Weise entstand eine einfache peripherische Alopecie; nämlich eine deutliche Phlogose etwa $1 \mathrm{~cm}$ rund um die Borke herum.

Gegen den 30. bis 40. Tag nach der Bestrahlung fiel die Kruste und es trat eine leicht blutende Ulceration mit speckigem Grunde zu Tage. Das Geschwür bedeckte sich bald mit einer neuen Kruste, die ziemlich in ihren Durchmessern reduziert erschien, aber gegenüber der ersten sich mehr in die Kutis vertiefte und adhärenter war.

Die einfache Alopecie erreichte in jener Zwischenzeit das Maximum ihrer Extension; später verkleinerte sie sich infolge Wachsens neuer Haare.

Gegen das Ende des zweiten Monates fiel noch die zweite Kruste. Aus dem speckigen Grunde des atomischen Geschwüres kam etwas wenig mit Blut gemischter Eiter mit foeditem Geruche. Von den Rädern rückten gegen die Ulceration Granulationen heran. Peripher von der Lösung wuchsen die Haare fortgesetzt in guter Quantität wieder. Neue Krusten folgten sich noch durch längere Zeit an der Ulceration, bis gegen Ende des dritten Monats die Veränderung in Heilung überging.

Die Heilung geschah durch Bildung einer dichten und derben Narbe, die fräher rosenrot, in der Folge weißlich war. Später noch traten einige Büschel dünner und spärlicher Haare an der vollständig gebildeten Narbe auf; dies geschah gegen Ende des vierten Monats.

In den folgenden Monaten, trotzdem sich die Haare regenerierten, war die alopecische Narbe immer von der normalen Haut unterschieden, 
denn die Haare nahmen nur langsam das Aussehen und die normalen Charaktere an.

Die Partie war statt mit homogenen Haaren in Bezug anf die Verteilung und Bildung lange mit Büscheln von Wollharen besetzt. Bei der letzten Maus unserer Serie, bei der Tötung, hatte die Bestrahlung vor 10 Monaten stattgefunden und die Vernarbung der Radiodermatitis datierte seit über 7 Monaten; trotz Ablauf so langer Zeit war die primäre alopecische und narbige Zone von der übrigen Haut durch das differente Aussehen des Haares unterschieden.

\section{Mikroskopische Befunde.}

Um in der besten Weise deutlich und systematisch die Auseinandersetzung unserer mikroskopischen Untersuchungen zu gestalten, werden wir die einzelnen Bestandteile der Haut getrennt behandeln.

Bei jedem Bestandteile werden wir die notwendigen Kenntnisse seiner normalen Strucktur voranschicken, um den Vergleich mit den Anomalien die hier beschrieben werden, zu erleichtern und um das Wesen derselben direckt zu verwerten. Die Kenntnisse der normalen Histologie, die wir anführen, schöpften wir außer aus den speziellen Abhandlungen der Anatomie und komparativen Histologie auch aus Untersuchungen, die wir eigens zu diesem Zwecke an normalen Mäusen anstellten, die uns in dieser Weise als Kontrolltiere dienten.

Vor der analytischen Untersuchung müssen wir hervorheben, dafi aus der Beschreibung der makroskopischen Veränderungen sich ergibt, daß in der Hautpartie, auf welehe das Radium wirkte, zwei Zonen zu unterscheiden sind, die von einander bezüglich der Entität der Veränderungen differieren. Seit der dritten Woche nach der Bestrahlung gut unterschieden, entspricht die eine dem früheren Geschwüre und die andere der einfachen Alopecie. Die erste nennen wir zentrale Zone der Bestrahlung und die zweite parazentrale Zone, indem wir die Aktionsphäre der vom Radium auf das Tier projektierten Strahlen berück. sichtigen.

Bei unseren Versuchen war die Vorkehrung getroffen, daß sich das Tier, wenn auch beschränkt, um sich selbst bewegen konnte und an einer bestimmten Stelle seines Rückens konstant bestrahlt wurde; die dieser Stelle benachbarten Partien wurden ununterbrochen mehr oder minder, je nach der eingenommenen Steliung, bestrahlt. Aus diesem Umstande gehen die verchiedenen Resultate hervor, welche uns ermöglichten, die Veränderungen in Bezug auf die Intensität der Bestrahlung studieren zu können.

\section{Epidermis.}

Unter normalen Verhältnissen besteht die Epidermis der Mans aus einer einzigen Schicht von kubischen Zellen, welche hie und da verdoppelt 
sein kann und auf der ein dünnes Stratum lucidum und oberfächlich eine spärliche Hornschicht liegt.

In den Schnitten der Haut, die wir 3 Tage nach Beginn der Bestrahlung entnabmen, zeigte die Epidermis zum großen Teile normales Aussehen und normale Struktur.

Hie und da findet maa aber in derselben statt einer einzigen Zellreibe zwei ; die tieferen aind größer mit ovalem Kerne und deutlichem homogenem Protoplasma. Im ganzen sind kleine Plaques epidermaler Verdickung, welche nach der sehwachen Vergrößerung (180 D.) ein oder $z$ wei mikroskopische Felder einnehmen.

Anderswo sind noch in der gleichförmigen Zellreihe eine kleine Gruppe verschiedener Zellen, welche so vereinigt sind, daB sie ein Knötchen (Fig. 2) bilden.

In einigen Schnitten zählt man entsprechend dem Epithelknötchen 4-5 Reihen von supraponiertien Zellen.

Die oberflächlichen derselben sehen fast normal aus; die tieferen dagegen haben die Ckaraktere junger Epithelzellen, reichliches und homogenes Protoplasma, ovaler und blasser Kern mit deutlichem Nukleolus, zartes Chromatin.

Das Stratum lucidum ist dentlich und differenziert sich wenig vom normalem. Die Hornschicht dagegen erscheint schon deutlich verdickt und besteht aus mehreren (Fig. 2) Lamellen.

Von der Haut, welche 5 Tage nach der Bestrahlung entnommen wurde, wählten wir für die histologische Untersuchung ein $3 \mathrm{~cm}$ langes und $1 \mathrm{~cm}$ breites Stückchen, entsprechend dem vorderen Drittel (Linea mediana) des Rückens.

Dieses Stückchen wurde in verschiedener Höhe in vertikaler Richtung zu seiner Länge zerschnitten; wir erbielten so Schnitte gerade der medianen Zone des Rückens. Bei der mikroskopischen Untersuchung fanden wir folgendes: mit der schwachen Vergrößerung und in allen Schnitten als erste auffallende Tatsache eine Dickenzunabme (Fig. 3) der Epidermis. Die Verdickung ist nicht äberall gleichförmig, sondern stärker im Zentrum und geringer an den Seiten der Schnitte, so daß, während im Zentrum die Fpidermis an gewissen Stellen die vierfache und fünffache Dicke als normal zeigt, gegen das Ende der Schnitte die Dicke der Epidermis kaum verdoppelt ist. Die Abnahme ist keine regelmäBige vom Zentrum gegen die Ränder, sondern dazwischen liegen Zonen verschiedener Dicke; im ganzen ist aber die zentrale Verdickung deutlich, da dieselbe in drei verschiedenen Schnitten vorkommt, so können wir schließen, daß die Ursache der Veränderung besonders längs der medianen Linie des Dorsums entsprechend der untersuchten Haut ihre Wirkung ausübte. Die Verdickung der Epidermis besteht deutlich aus zwei Faktoren, aus einer numerischen Zellvermehrung und aus reichlicher Hornstratifikation.

Bei der Untersuchung der Epidermis mit der stärkeren Vergrößerung finden wir, daß die Hornschicht aus ebensovielen supraponierten Arch. f. Dermat. u. Syph. Bd. XCVII. 
Lamellen besteht, welche in den Schnitten das Bild von gröblich punktierten, unter einander sich durchschneidenden Linien wiedergeben, die im ganzen einen der Epidermis parallelen Lauf beibehalten. Die Hornlamellen nehmen intensiv die Farbe des Hämatoxilins an. Sie trennen und zerreißen sich in den Prozessen infolge der Verhärtung and Inklusion leicht, so daß wir in den Präparaten nicht eine kontinuierliche Schicht, sondern mehr oder minder breite Inseln haben. Unter der Hornsubstanz erscheint das Stratum lucidum sehr kompakt und nennenswert verdickt. Es ist von fast glasiger Struktur und tingiert sich auch intensiv. Wo dasselbe in das Stratum granulosum übergeht, bemerkt man kaum die Zellen in fortgeschrittener Transformation; man erkennt dieselben als sehr oblungierte und intensiv tingierte Figuren, welche als Schatten die homogene Suhstanz des Stratum lucidum unterbrechen. Das Stratum granulosum ist bald sehr deutlich, bald kaum angedentet. $W_{0}$ es mehr deutlich ist, dort besteht dasselbe aus einer oder zwei Reiben von intensiv abgeflachten und schlecht konturierten Zellen, in denen mehr als etwas anderes dicke Eleidinkörner auffallen, die eine spezielle Affinität für das Eosin haben.

Der Rest von chromatischer Kernsubstanz tingiert sich diffus mit Hämatozylin.

Stratum lucidum und Stratum granulosum bilden eine Art mehr oder weniger dicke Rinde, unter welcher sich die proliferierenden Epidermiszellen befinden. Der Proliferationsgrad der Epidermiszellen ist an den einzelnen Stellen verschieden. In den Initialgraden konstatiert man statt der normalen einzigen Zellschicht eine doppelte Schichte. In den mehr fortgeschrittenen Graden sind drei, vier oder noch mehr (Fig. 3) Schichten.

Die oberflächlichen Schichtzellen sind meistens abgeflacht; ihr Kern, manchmal dünn oder oblungiert, wird immer diffus und intensiv gefärbt. Die tieferen dagegen sind schöne, cylindrische, palissadenartige Zellen mit gezähnter Einpflanzungsbasis, feinst gekörntem Protoplasma und einem deutlichen blasigen Kerne mit einem oder mehreren glänzenden Nukleoli und feinem, zarten Chromatin. Durch Zwischengrade gelangt man von einem Typus zum anderen dieser Zellen, mit größerer Deutlichkeit, wenn mehr als zwei Schichten sind, immer deutlich jedoch, wenn auch nur zwei Schichten sind. Hie und da konstatiert man in der Basalschicht zwei intensiver tingierte Kerne, die die Initialphase einer indirekten Teilung andeuten. Außerdem finden sich deutliche Mitosen.

Dort wo sich die Epidermis in der äußeren Epithelscheide der Haare fortsetzt, ist die Verdickung der Zellreihen, welche die Scheide bilden, deutlich; darüber werden wir aber bei den Haaren sprechen.

Von der Maus, welche 10 Tage nach Beginn der Bestrahlung getötet wurde, trugen wir das Hautstückchen entsprechend dem vorderen Drittel des Rückens ab und teilten dasselbe, wie im vorigen Falle in Sohnitte. 
Untersuchen wir mit des: schwachen Vergröberung die verschiedenen Schnitte, so finden wir, daB die Epidermis fast äberall verdickt ist. Im ganzen ist die Verdickung nicht nennenswert und sie bewegt sich fast um das doppelte des normalen herum. An einigen Stellen ist sie aber stärker und bildet Zellplaques, die in den Schnitten ziemlich die Linie der Oberfäche überragen. Hie und da ist die Epidermis normal dick; ja an einigen Stellen ist sie fast verdüunnt. Überall liegt der Zellschicht eine bedeutende Hornschicht auf, die aus Lamellen bestebt; dieselben erscheinen auch mit der schwachen Vergrößerung als gröbliche Linien, die untereinander sich schräg schneiden.

Die Untersuchung der Epidermis mit der starken Vergrößerung ergab einen Befund, der ähnlich demjenigen ist, welchen wir bezüglich der Haut 5 T. n. B. beschrieben haben, mit dem einzigen Unterschiede, daß die Tatsachen der epithelialen Proliferation und der körnigen Transformation weniger ausgesprochen sind. Ohne Details zu wiederholen konstatieren wir, daß eine beträchtliche Hornschicht, ein Stratum lucidum und ein Stratum granulosum deutlich vorixommen; dann zwei oder drei Schichten von Zellen auf dem Wege der Evolntion und tief eine Basalschicht mit galisaden Zellen, wo sich Figuren sowohl direkter als auch indirekter Teilung sich finden.

Bei der Maus 14 Tage nach der Bestrahlung gingen in der Haut die Veränderungen frühzeitig vor sich, da schon am 14. Tage die Alopecie mit phlogistischen-exudativen Erscheinungen, die von kleinen, blutigserösen, auf einer fast zweihellerstückgroßen Fläche zerstreuten Krusten dargestellt waren, vorkam.

Es wurde ein Stückchen Haut, das in der Mitte die deutlich veränderte Zone und rund herum die umliegenden Zonen enthielt, entnommen und in der Weise geschnitten, um separat die zentrale und die parazentrale Zone studieren zu können.

In den Schnitten der zentralen Zone haben wir im allgemeinen bezüglich des Epidermis folgenden Befund. An einigen Stellen ist keine Spur mehr von Epithelzellen, aber die Hautfäche ist mit Knötchen, die aus exsudativen Elementen (Leukocyten Fibrin und Blut, welche mit Bakterien vermischt sind) bestehen, bedeckt. An anderen stellen ist die Epidermis zu wenigen, stark abgefachten und oblungierten Zellen reduziert, die nicht regelmäßig aufeinader liegen, sondern an der Oberfiäche der Cutis, die entblößt wird, zerstreut sind.

Diese Zellen, außer daß sie die Charaktere der Keratohyalindegeneration präsentieren, wodurch sie als involvierte Elemente erscheinen, sind unregelmäßig groß, so daß man neben stark verdünnten Elementen auch gequollene Elemente und wahre mononukleäre Riesenzellen konstatiert werden. Denselben liegt eine sehr dichte und aus gröblichen leicht zerstückelbaren Lamellen bestehende Hornschicht a uf.

Von diesen Stellen von deutlicher Atrophie der Epidermis gelangen wir stufenweise zu Partien, wo statt einer Verdünnung der entgegengesetzte Prozeß d. i. eine Verdickung der Epidermis sich findet. In der 
Fig. 7 ist gerade der Übergang der epithelialen Atrophie (rechts) zur Hypertrophie (links) abgebildet. Wier finden hier eine reichliche Hornschicht, das Stratum lucidum und granulosum sehr deutlich, und unter denselben zwei, drei oder noch mehr Schichten von Epithelzellen von denen die oberflächlicheren abgeflacht sind; die tieferen zeigen die Merkmale der Palissadenkeimzellen.

In den Schnitten der parazentralen Zone ähnelt der mikroskopische Befund jenem von der Haut, die 5 und 10 Tage bestrahlt wurde, sehr.

Auch hier haben wir das deutliche Bild der Epidermisproliferation und der Hyperkeratose gefunden. Zum Nachweise der ersteren dienen die häufigen Mitosen in der Basalschicht, welche sehr gut in den in Zenkerscher Flüssigkeit fixierten Stückchen zu Tage treten.

Im allgemeinen haben wir bei der Untersuchung der verschiedenen Schnitte der Epidermis, von der Peripherie gegen das Zentrum der Veränderung, den Beginn einer Hyperplasie der Epidermis an den mehr exzentrischen Stellen konstatiert; diese Hyperplasie nimmt allmählich stufenweise durch eine gewisse Strecke zu und übergeht allmählich, wie man sich dem Zentrum der Veränderungen nähert, zur Atrophie mit Disepithelisierung und Entblößung des Corium mit nachfolgender Exsudation über.

An der Haut der Maus, die 19 Tage nach dem Beginne der Bestrahlung getötet wurde, stellt sich die Alopecie ein. Die Zone, auf welche das Radium mit größerer Intensität eingewirkt hatte, war durch die Charaktere der ausfallenden Haare und durch die beträchtliche Desquamation erkenntlich. Auch hier war es möglich, die zentrale Zone von der parazentraleu zu unterscheiden. Das Charakteristische der zentralen Zone in der Epidermis besteht in einer außergewöhnlichen Hornschicht, welche von Lamellen gebildet ist; an der kutanen Fläche ist eine parallele Ondulation. Unter der Hornschicht ist das Epitel zu einigen stark abgeflachten Zellen reduziert, deren Kern oft sich in Pyknose befindet; das Protoplasma sieht glasig aus und enthält Eleïdintropfen. An einigen Stellen ist das Epithel auch vollständig verschwunden und die beträchtliche Hornschicht bedeckt allein die Cutis.

In der parazentralen Zone ist die Hornschicht der Epidermis auch nennenswert; dieselbe ist größtenteils stark verdickt auch infolge der Stratifikation des Epithels, das noch die Charaktere der abnormen Proliferation zeigt, welche bei den vorherigen Beschreibungen angegeljen warde.

Bei der Haut der Maus, die 20 Tage nach der Bestrahlung abgetragen wurde, ist der Befund zum großen Teile dem soeben angeführten analog mit dem Unterschiede, daß die zentrale Zone, anßer der ausgesprochenen Hyperkeratose und Disepithelisierung, auch kleine exsudative Herde präsentiert, die aus den gewöhlichen Entzündungselementen (rote und weiße Blutkörperchen, Fíbrin, Bakterien, Detritus) bestehen. Auch hier reigt die exzentrische Zone die Epidermis in einem Status von Proliferation. 
Bei der Haut, welche $20^{\circ}$ Tage bestrahlt wurde, bleiben von der Epidermis, da sich das Geschwür in der zentralen Zone schon gebildet hat, nar einige Spuren unter den Krusten des Exsudates zurück; letzteres bildet allein die ober日ächliche Schicht der entsprechenden Haut.

An der Grenze zwischen der zentralen und der parazentralen Zone finden wir Stellen, die zwar nicht mit Exsudat bedeckt aber vollständig obne Epidermis sind; letztere ist deutlich in ihrer Gänze abgefallen und die Cutis ist entblößt oder kawm mit einer Schicht einer hyalinen-kornealen Substanz bedeckt, welche die letzten Spuren des keratinisierten und exfolierten Epithels darstellt.

Nach einer kurzen Strecke aber, zur parazentralen Zone übergehend, finden wir ein üppiges Epithel in mehreren Schichten. An den Stellen, wo die Verdickung der Epidermis einen höheren Grad erreicht hat, fällt vor allem die Tatsache auf, dab das Stratum Iucidum und die Hornschicht sich besonders entwickeln und daß die Zellen der oberflächlichen Schichten eine meriliche keratobyaline Involution erlitten baben.

In diesem Stadium beginnt die Regeneration des Haares, sei es durch Ausläufer aus der Epidermis, sei es durch die Proliferation in den yom alten Haare entleerten Epithelscheiden; die Hyperplasie mit cystischer Dilatation der Talgdrüsen wird akzentuiert, so daB der ganze epitheliale Apparat einen metaplastischen Charakter angenommen hat and gewissen kutanen Neubildungen (Keratome, Epitheliome, Cancroide) gleicht. In Fig. 5 ist diese Metaplasie der Haut augebildet.

Solche Veränderangen finden wir in jenem Teile der Haut, die 26 Tage nach der Bestrahlung makroskopisch von vollständiger einfacher Alopecie charakterisiert wird; in dieser Zeit ist die Epidermis auch durch eine gewisse Strecke an der Peripherie beteiligt, wo nicht mehr vollkommene Alopecie sondern nur Haarausfall vorkommt.

In dieser exzentrischen Zone finden wir, daß die Verdickung der Epidermis noch merklich ist und durch eine Zell- und Hornschicht (Fig. 4) charakterisiert wird.

Die Verdickung nimmt peripher ab and die Epidermis wird allmählich normal dick.

Die Haut, welche 37 Tage nach der Bestrahlung untersucht wurde, entnahmen wir der spontan abgestorbenen Maus, in welcher wir außer der Atrophie Marasmus und Pneumonieherde feststellten.

Wir fanden, daß die Epidermis an der Stelle des Schorfes vollständig verschwunden war; an ihrer Stelle trafen wir die bistologischen Merkmale des entzündlichen-ulcerativen (Fig. 14) Prozesses. Um den Schorf ist die Epidermis erhalten und geschichtet, aber in geringeren Grade und durch eine viel kürzere Strecke als in dem vorausgegangenen Falle. Im ganzen gewinnt man den Eindruck einer geringeren Reaktion des Epithels gegenüber den anderen Fällen.

45 Tage nach der Bestrahlung fiel schon die erste Kruste; es bildete sich eine zweite, ein wenig enger als die vorherige; infolge dessen müssen wir in diesem Stadium und in den Segmenten den Reparations- 
prozeß außer dem weiteren Verlaufe des wahren radiodermatitischen Prozesses, der seiner Lösung entgegengeht, in Betracht ziehen.

Bei der Untersuchung einer Epidermispartie, die sich vom Zentrum des Schorfes peripher bis zur gesunden Haut erstreckt, finden wir vor allem, daß die Epidermis entsprechend dem Schorfe vollständig fehlt. Erst außerhalb des letzteren, dort wo der NarbenprozeB vorkommt, ist die Epidermis geschichtet und sehr dicht mit Digitationen im tieferen Teile, welche sich in der Cutis tortsetzen. Weiter exzentrisch finden wir die Epidermis durch eine gute Strecke immer verdickt und geschichtet. In ihrer histologischen Konstitution finden wir verschiedene Schichten, Stratum basale, mucosum, granulosum, lucidum und corneum, mit den entsprechenden, jetzt zur Genüge bekannten Charakteres.

Endlich geht man langsam zur normalen Epidermis über.

Einen ähnlichen Befund finden wir bei der Untersuchung der Haut der Maus, welche 70 Tage nach der Bestrablung getötet wurde. Hier finden wir auch vom Schorfe gegen die Peripherie fortschreitend, da $B$ die Epidermis vollständig in der Gegend des Schorfes fehlt; merklich verdickt und geschichtet finden wir sie (Fig. 15) in der Narbenzone.

Verdickt ist die Epidermis durch eine gewisse Strecke peripher, aber im Ganzen ist ihre Dicke im Vergleiche der entsprechenden Zone im Stadium 45 T. n. B. merklich geringer und umschriebener. Schließlich sind normale Verhältnisse.

Die Hant, die 71 Tage bestrahlt wurde, gewannen wir von einer Maus, die einem natürlichen Tode mit akzentuiertem Marasmus erlag.

In derselben war die zentrale Zone durch eine lange Strecke mit einer Kruste bedeckt. In der umliegenden Zone war die Epidermis aber durch eine kurze Strecke hypertrophisch; in nicht weiter Entfernung waren normale Verhältnisse. Auch bei dieser Maus hat man, wie bei jener, die nach 37 Tagen starb den Eindruck einer spärlichen Reaktion der Epidermis und der anderen Bestandteile der Haut.

Bei der Hant, die wir 95 Tage nach der Bestrahlung untersuehten, war die Veränderung des Radiums vollständig vernarbt. Unsere Untersuchung erstreckte sich auf ein Stückchen zwischen dem Zentrum der Narbe und der vollständig gesunden Haut.

Der mikroskopische Befund bezieht sich auf eine Narbenzone und auf eine Zone, in der die primäre Alopecie durch die Reproduktion des Haares dem Verschwinden entgegengeht.

Bei der Untersuchung finden wir die Epidermis dieser Gegend merklich verdickt und aus den bekannten Schichten zusammengesetzt. Die Epidermis der Narbe, in ihrer tiefen Schichte, sendet Ausläufer, welche in die Cutis sich ein wenig vertiefen; die Cutis erlangt ihrerseits eine papilläre Oberfläche, wodurch sie dem Papillarkörper der normal geschichteten Haut ähnlich wird. Diese papilläre Verteilung (Fig. 16) differenziert diese sekundäre oder Narbenhypertrophie von der Hypertrophie des ersten Stadium, welche wir als hauptsächliche Tatsache von Reaktion des Epithels gegen die Bestrahlung festgestellt haben, da bei 
der primären Hypertrophie die Basalschicht in einer regulären Linie angeordnet ist und das Corium an das Epithel ohne Erhehungen grenzt. Die narbige Hypertrophie wntersoheidet sich noch durch eine essentielle Besonderheit von der primären Hypertrophie der Epidermis, durch die Tatsacbe nämlich, daß sie nicht eine übertriebene Stratifikation von Hornlamellen (Hyperkeratose) aufweist, obgleich das Stratum lucidum und granulosum ansgesprochen sind.

Außerhalb der Narbenzone ist dort, wo das Haar mehr oder minder vollständig gewachsen ist, die Epidermis streckweise noch verdickt. Ibre Dicke ist aber auf zwei oder drei höchstens auf vier Schichten in unmittelbarer Nähe der Narbe beschränkt.

Die Untersuchung der Epidermis 4 und 5 Monate nach der Bestrahlung ergab folgenden einfachen Befund: mäBige Stratifikation der Epidermis der Narbe, hierauf graduelle Restitution der normalen Verhältnisse in der Epidermis (Fig. 17) um die Narbe. Die Stratifikation der Narbe wird noch allmählich mit dem Älterwerden der Narbe geringer bis die Epidermis 10 Monate nach der Bestrahlung normale Verbältnisse wieder aufweist; es bleibt nur dort eine mäbige Verdickung zurück, wo die Uleeration intensiver war; dies geht in Fig. 18 hervor, welche eine Photographie des letzten Stadium der Veränderungen wiedergibt.

Die Veränderungen in der bestrahlten Epidermis, die wir bisher analytisch beschrieben haben, können folgendermaßen wiederholt werden.

In der zentralen Zone manifestiert sich drei Tage nach der Bestrahlung ein proliferativer ProzeB, der durch Bildung von Knötchen oder kleinen Plaques epithelialer Verdickung ausgedrückt wird. Die Proliferation wird in den folgenden Tagen bis zum 10. Tage intensiver, so daß die Epidermis mehrfach geschichtet wird. Nach dem 10. Tage wird der Neubildungsprozeß langsamer; der Prozeß der zelligen Involution, welche durch die Hyperkeratose charakterisiert ist, die auch makroskopisch infolge der furfurösen Desquamation konstatierbar ist, akzentuiert sich.

Zwischeu dem 14. und dem 20. Tage tritt, sei es durch das Stärkerwerden der keratinischen Involution, sei es durch die Aufösung der Neubildung, das vollständige Ausfallen der Epidermis. Es entsteht ein torpides Geschwür, das zur Heilung lange Zeit braucht; mit der Restrinktion desselben beginnt die Phase der Reparation der Epidermis. Von den Rändern des Geschwürs rückt ein neues mehrfach geschichtetes Epithel heran, das allmählich den Defekt bedekt; es entsteht eine Narbe, die sich im Verlaufe des dritten Monates nach der Bestrahlung vervollständigt.

In der parazentralen Zone (weniger intensive Bestrahlung) kommt auch die epitheliale Proliferation vor; dieselbe beginnt später (10.-14. Tag) und ist eine mehr langsame, denn sie dauert 60-70 Tage.

In dieser langen Zeit aber erreicht die von diskreter Hyperkeratose konkomitierte Hyperplasie der Epidermis hohe Grade, daß sie eine 
mehrschichtige kallöse Epidermis wird, welche oft die keratomatöse und cancroide Metaplasie streift.

In dieser Zone fällt die Epidermis nicht ab, sondern es treten in sie langsam normale Verhältnisse, ohne das Corium entblößt zu lassen.

Nach der schematischen Darstellung des Verlaufes der Epidermisveränderungen, müssen wir hervorheben, $\mathrm{da} \beta$ wir bezüglich der Rapidität und Intensitat nicht beträchtliche aber deutliche individuelle Variationen beobachtet haben. Abgesehen von kleinen Unterschieden in den Effekten der Bestrahlung des Tieres, die der verschiedenen Entwicklung des Tieres und seiner Beweglichkeit im Apparate zuzuschreiben sind, abgesehen von diesen Differenzen, die wir auf das Minimum zu reduzieren bestrebt waren, glauben wir, daß die beobachteten Variationen in Beziehung mit dem individuellen Faktor von Resistenz resp. Reaktion gegen die Radiumwirkung stehen; auf denselben Faktor ist wahrscheinlich auch die Tatsache zu beziehen, daß von 16 Mäusen zwei an Marasmus zu Grunde gingen, während der Allgemeinzustand der übrigen 14 ein guter war. Trotzdem wir nicht in der Lage sind zu beurteilen, welchen Anteil das Radium in der Hervorrufung, sei es primär, sei es sekundär, des Marasmus gehabt hat (London hat eine ähnliche Wirkung dem Radium zugeschrieben) so steht dennoch die Tatsache fest, daß bei denselben Mäusen mikroskopisch die Reaktion der Epidermis eine relativ sehr spärliche war; dies kann sehr gut durch eine sehr geringe vitale Energie des Organismus bedingt sein, wie wir es seinerzeit betont haben.

\section{Cutis.}

Die Cutis der Maus besteht aus faserigem Bindegewebe mit spärlichen Zellen. Mit den Bindegewebsfasern verflechten sich vereinzelte elastische Fasern, welche in der Umgebung des Follikels, für den sie eine Verstärkungshülle bilden, dichter sind.

Am Haarbulbus entspringen auch die Musculi arrectores pilorum, welche die Cutis diagonal durchziehen. Die Cutis ist mit einem ziemlich reichlichen Netz von Blut und Lymphgefäßen für die Ernährung und den Stoffwechsel der Haut ausgestattet.

Zwei oder drei Tage nach Anfang der Bestrahlung beginnt man eine leichte Vermehrung der Kerne $z$ wischen den etwas gequollen erscheinenden Bindegewebsbündeln zu bemerken. In kurzer Zeit, gegen den fünften Tag, wird der Prozeß der zelligen Infiltration deutlicher; die Cutis ist reich an verschieden geformten Kernen. Letztere sind größtenteils Kerne vermehrter Bindegewebszellen, aber dazwischen mischen sich auch Kerne von Wanderzellen, die aus den in dieser Zeit dilatierten Gefäßen stammen. Seröse Imbibition komomittiert die zellige Infiltration, so daß die Dicke der Cutis vermehrt erscheint.

Wenn Riesenzellen bis zur Epidermis gelangen, so dringen sie in die Basalschicht derselben ein. 
Die hyperplastischen. Teränderungen der Cutisbündel sind auch zwischen den fibrösen Bündeln des Haarfollikels deatlich. Diese Veränderungen in der seit 5 Tagea bestraliten Haut sehen wir in Fig. 9 deatlich.

Die Proliferation der Zellen in den Bindegewebsbündeln und besonders im fibrösen Teile des Follikels (Fig. 9) schreitet durch einige Zeit fort und manchmal vermebrt sie sich noch. Allmählich mit dem Fortschreiten der Atrophie der Epidermis akzentuiert sich auch die entzündliche Infiltration darch die Leukocyten, bis nach dem Abfallen der Epidermis wir die gewöhnlichen Verhältnisse der Entzündung finden.

In der Cutis entwickelt sich dann der gemeinhin als Radiumdermatitis bekannte Prozeß, der durch eine besondere Trägheit im Verlaufe und durch seine grobe Langsamkeit bei der Heilung charakterisiert ist. Nach der Atrophie und dem Schwunde der Epidermis wird die Entzündung auch durch die Tatsache begünstigt, daß die entblößte Cutis allen äußeren Reizen und Schädigungen ausgesetzt ist. Mikroskopisch hat man den Befund einer chronisehen Wande. Wir finden Massen von Zell. detritus vermischt mit Blut, Fibrin und Bakterien. In der Tiefe sind teils konsernierte, teils der Zerstörung entgegengehende Leukocyten in Überfluß; es sind noch Zelldetritis, Fibrin und Bakterien. Allmählich wie der Prozeß zur Heilung fortschreitet, nehmen die exsudativen Elemente $a b$, während die charakteristischen jungen Elemente des Granulationsprozesses in erster Linie hervortreten.

Bei der vollständigen Heilang wird die Cutis langsam wieder zu einem fibrösen Gewebe, das noch kompakter als die normale Cutis ist. Wir heben schon jetzt hervor, dab zwischen den Fasern der Cutis, sei dieselbe entzündet, sei sie vernarbt und retrabiert, die Zellen der Papille des ausgefallenen Haares unterschieden werden, welche in der Form eines von den fibrösen Bündeln des Follikels umgebenen Knötchens (Fig. 12) gruppiert sind.

Während der Entwicklung der Radiumdermatitis werden die fibrösen Bündeln deutlich gelöst und viele Fasern, von dem Eindringen der entzündlichen Infiltration zerstreut, gehen wahrscheinlich zu Grunde. Wir sagen "wahrscheinlich“, weil wir uns über die Permanenz der alten Fasern irn Narbengewebe keinen Begriff machen können.

Bezüglich der elastischen Fasern ist die Orientierung wegen der spezifischen Tinktionsmethoden leichter; wir können sie in fibrösem Gewebe deutlich machen. Diese Fasern beweisen eine große Resistenz gegen die deletäre Wirkung des nekrotischen entzündlichen Prozesses. Tatsächlich finden wir nicht nur in den verschiedenen Stadien der Radiumdermatitis dieselben im entzündlichen Gebiete zerstreut, sondern auch zu gröblicheu Bündeln und Haufen im Narbengewebe vereinigt, besonders um das papillare Knötchen, zusammen mit den Resten der Bindegewebsfasern des Follikels.

Die Blutgefäße der Cutis reagieren vielleicht zuerst auf die Radiumwirkung, denn wir finden dieselben sofort nach der Bestrahlung dilatiert. 
In den ersten Tagen (3.-5. T. n. d. B.) treffen wir eine Erweiterung der Capillaren und eine reichliche Durchblutung an. Kurz darauf lassen die Gefäße Leukocyten und Serum heraustreten, welche das bestrahlte Gebiet infiltrieren. Das Gefäßkaliber wird in der Folge noch weiter, es bildet sich ein dichtes Capillarnetz, das die untere Fläche der Epidermis erreicht. Der Blutzufluß ist reichlich und die Gefäßwände werden aufs Höchste gedehnt. Jedoch in der Struktur der Gefäßwände selbst bemerkt man keine deutlichen Veränderungen, weder in den ersten Stadien noch in der Akme des Exsudationsprozesses.

Sobald sich aber das Geschwür gebildet hat, sieht man dagegen, daß dort, wo der destruktive Prozeß tiefer einzudringen droht, in den Blutgefäßen von einem gewißen Kaliber ein Obliterationsprozeß einsetzt, der offenbar die Blutverluste verhindert, zu denen die Erosion Veranlassung geben könnte.

Mit dern Fortschreiten der Vernarbung reduziert sich neuerdings das GefäBkaliber, bis in den gebildeten Narben die Vaskularisation normale Verhältnisse aufweist.

Die Musculi arrectores pilorum leisten der Einw rkung des Radiums zähen Widerstand, denn sie erscheinen während des entzündlichen Prozesses unversehrt, wenn nur nicht die Ulceration alles zerstört.

In der vernarbten Cutis finden sich die Musculi arrectores auf den fibrösen Resten des Haarfollikels.

Was wir bis jetzt beschrieben haben, bezieht sich auf jenen Teil der Cutis, der am meisten der Radiumwirkung (Zentralzone) ausgesetzt war und somit nicht die Folgen des ulcerativen Prozesses erlitten hatte. In der umliegenden Cutis (parazentrale Zone) finden wir kaum eine mäßige zellige Infiltration und eine vermehrte Vaskularisation um das Geschwür; es ist dies wahrlich eher ein Effekt der entzündlichen Reaktion selbst als der eigentlichen Radiumwirkung.

\section{Haare.}

In dem Vorwort über die normale Histologie des Haares müssen wir außer der Konstitution des Haares selbst auch seine emtryonale Entwicklung und vor allem seine Erneuerung im extraembryonalen Leben, nämlich jene verschiedenen Momente, welche das Phänomen des Haar. wechsels bilden, besprechen.

Während aber die embryonale Entwicklung und die Histologie des erwachsenen Haares gut definiert sind und diesbezüglich unter den Histologen keine Meinungsverschiedenheit besteht, kann man dies betreffs des Haarwechsels nicht behaupten, über deren Mechanismus noch jetzt viele Gegensätze vorhanden sind.

Der Ausfall und die Regeneration des Haares, welche wir hier als Folgen der Radiumwirkung studieren werden, stehen mit dem physiologischen Wechsel in einem solchen innigen Zusammenhange, daß wir 
nicht unterlassen konnten, uns ein wenig mit dem Wechsel selbst $\mathrm{qu}$ befassen, um die fundamentala plysiologische Basis festzustellen, anf die wir die vom Radium bedingten Erscheinungen verwerten.

Das Schema des Haeswechsels bei der Maus paBt sich den Lehren der Mehrzahl der Forscher and unseren Beobachtungen an. ${ }^{1}$ ) Wir können hinzufügen, dab die infolge der Radiumwirkung beobachteten histopathologischen Prozesse, die ron uns genau studiert wurden, uns öfters halfen, gewisse Momente des physiologischen Prozesses selbst zu interpretieren.

Dies voranggesetzt, werden wir zuerst von der normalen Histologie in großen Zügen die embryonale Entwicklung des Haares wiedergeben; dann werden wir das erwachsene Haar und zuletzt das Haar im Wechsel beschreiben.

Embryonale Entwicklung des Haares. Im Foetalleben entwickelt sich das Haar aus einem epithelialen Knopf, der sich von der Epidermis in das mesodermale Gewebe vertieft und eine Gruppe von Zellen, die zur Bildung der Papillen bestimmt sind, bedeckt. Von dem Wachsen des epithelialen Kropfes und von der Differenzierung seiner Teile bildet sich der Bulbus des Haares mit den Scheiden.

Bildung des erwa chs en en Haares. Das Haar besteht wesentlich aus dem eigentlichen Haare oder epidermalen Teile und aus dem Follikel oder mesodermalen Teile, der auch das Ernährungsorgan des Haares, die Papille, bildet.

Das eigentliche Haar bestcht aus dem Stengel und Bulbus; letzteres ist mit den epithelialen Scheiden, der inneren und äußeren, umbüllt. Der untere Teil des Bulbus ist im erwachsenen Haare aufgequollen und besteht aus Zellen, welche die Haarmatrix bilden. Die Papille buchtet sich in den Bulbus ein und paßt sich in der gebildeten Ausbuchtung an. Bei der Maus durchzieht das Haar während der Entwicklung die ganze Cutis und sein unterster Teil (aufgequollener Bulbus) ruht auf den Zellen, welche die Cutis von dem Haarbalg trennt.

$\mathrm{Ha}$ arwechsel. Das Haar zeigt im physiologischen Wechsel eine Reihe von Veränderungen, die die Fähigkeit haben, dasselbe zuerst in ein Kolbenhaar umzubilden und es dann aus der Scheide auszutreiben. Der ganze Prozeß geht von dem Stillstand in der Aktinität der proliferativen Zone; daher die Volumsveränderung des Bulbus und der Schwund des Markes des Haares, das gänzlich verhornt auch in seinem zentralen Teile übrigbleibt. Der Bulbus beginnt in der Folge in der Cutis emporzusteigen und seine Anschwellung trennt sich von der Papille; letztere kommt aus ibrer Nische heraus und der untere Pol des Bulbus kugelt sich ab wie die Spitze eines eingestulpten Handschubfingers. Der Bulbus steigt weiter empor und läßt hinter sich eine Reihe von Epithelzellen,

1) Für den Haarwechsel benützen wir die Abhandlungen von Hertwig, Kolliker, Stöhr, Ellenberger und Schneider; außerdem die Monographien von Anburtin, Spueler, Garcia, Kölliker, Stieda, Veneziani and V. Ebner. 
das Residium der germinalen Zone (Epithelialwurzelzylinder von Ga r cia); an ihrem unteren Ende ist die Papille in eine rundliche Gruppe von sehr bupierbaren und gedrängten Zellen umgewandelt (Fig. 9), die wir papillares Knötchen bezeichnen werden. Zu gleicher Zeit entsteht die Atrophie der Schichten der inneren Scheide, so daß das Haar nur von der äußeren Wurzelscheide beschützt wird, die aus zwei Schichten oblungierter und verkleinerter Zellen besteht. Wenn die Produktion neuer Zellen von dem Grunde des Bulbus nicht mehr stattgefunden hat, trotzdem die Verhornung der alten fortgesetzt worden ist, so gelangt man zu dem Punkte, in dem das Haar an seinem Einpflanzungsende die Form eines Kolbens erlangt. Bei einem weiteren Älterwerden des Haares entsteht aus dem Kolben eine Besenfigur wegen der fibrillären Figur der Wurzel. Während so die Trennung des Haares reif wird, atrophisiert sich die epitheliale Reihe, die kürzer wird und nach sich das verdichtete und verkleinerte papilläre Knötchen zieht.

Andererseits akzentuieren sich im Haarfollikel die fibrösen Bündeln und es stellt sich eine Hypertrophie des Follikels selbst ein; von diesem verlängern sich einige Bündeln, umbüllen das papillare Knötchen und senden einen Ausläufer in die Tiefe in der Form eines fibrösen Stranges, der ein Frenulum um den ganzen Follikel (Haarstengel, Wertheim) bildet.

Die Hypertrophie des Follikels würde das Emporrücken des Kolbens hervorbringen oder begünstigen und zwar durch die Kontraktion der Fasern, von denen die inneren halsbandartig und zirkulär angeordneten die Funktionen eines glatten Muskels (v. Ebner) hätten.

Nach vollständiger Atrophie trennt sich der Stengel und derselbe wird hinausgetrieben.

Es tritt dann der Regenerationsprozeß auf, der von den restlichen Epithelzellen der Reihe (alte germinale Zellen) oder von den tieferen Zellen der äußeren Scheide ausgeht. Aus denselben bildet sich ein Zellstrang, der bald in Kontakt mit der Papille tritt - nach einigen Forschern mit der aiten, nach anderen mit einer neugebildeten - und dieselbe bedeckt wie im embryonalen Prozesse. In der Folge vertieft sich die neue Zellreihe, welche vor sich die Papille drängt, unten in der Cutis, während nach oben sie sich bis zur Erreichung der Epidermis erhöht. Unter den zentralen Zellen der Reihe entsteht eine Differenzierung, so dab sich allmählich ein neves Haar bildet.

An den Veränderungen, die im Haare infolge der Radiumwirkung auftreten, nehmen zu gleicher Zeit alle Bestanateile des Haares selbst teil. Nach der Beschreibung der Veränderungen der Epidermis und der Cutis wird es uns leicht sein, die Veränderung des Haares, sei es des Epithels, sei es des Bindegewebes, zu begreifen.

Wir haben gesehen, daß an der 3 Tage nach der Bestrahlung entnommenen Haut Veränderungen der Epidermis vorkommen und zwar eine gewisse reichliche korneale Produktion, Verdickungen unter der Form 
von Knötchen oder Epithelplaques. Dagegen ist in jener Zeit im Haare alles in Ordnung.

In der seit 5 Tagen bestrahlten Haut beginnen die Veränderungen auch im Haare deutlich zu werden; an denselben nehmen sowohl das Epitbel als anch das Bindegewebe teil in dem in der Epidermis und in der Cutis konstatiertem Maße, Die Anteiluahme der Epithels äußert sich uns vor allem durch eine Veränderung im Aussehen der Zellen der äußeren Wurzelscheide, die rundlich werden, mit aufgequollenem Protoplasma; der blasige Kern ist sehr deutlich mit Chromatingerüst und Nukleolus; die Zellen selbst machen den Eindruck ron funktionierenden oder aktiven Zellen. Das Wiedererwachen ihrer Aktivität zeigt sich tatsäch. lich durch eine deutliche Proliferation im höheren Teile der Wurzelscheide. Diese Proliferation setzt sich mit der in der Epidermis beschriebenen fort, die, wie jene, aus zahlreichen Figuren direkter oder indirekter Teilung aus einer Verdickung des oberen T'eiles der Epithelscheide konstatiert wird. Im Haarfollikel sind zweifellose Veränderungen. In der Haut, auf welche sich unsere Beschreibung bezieht, sind dieselben sehr ausgesprochen und sie entsprechen wesentlich den betreffenden in der Kutis. Wir finden, wie in der Cutis, eine beträchtliehe Vermehrung der Bindegewebezeilen, so daB die ganze Wand des Follikels dioker und reichlicher an spindelförmigen Zellen wird, die mit ihrer größeren Achse im Sinne der Haarlänge geordnet sind.

Die Verdickung äußert sich am meisten gegen den Grund des Follikels und bildet um die distalen Teile des Haares einen merklichen fibrozellulären Kreis, der sich im Haarbalge fortsetzt. Es entsteht so ein ausgesprochener Strang, durch welchen man die Schnitte der dilatierten Blutgefäße sieht.

Auch das papillare Knötchen zeigt in diesem Stadium das Bestreben, an den proliferativen Veränderungen des Haarrestes teilzunehmen. Und wirklich, dasselbe erscheint gegenüber der Norm dicker. Die Zellen, die es bilden, erscheinen mehr deutlich und zeigen einen schönen Kern von lymphoider Struktur. Fig. 9 reproduziert einen Haarschnitt in diesem ersten Stadium der Veränderungen, die aus Proliferationserscheinungen sowohl des Epithels als auch des Bindegewebes bestehen.

Wollen wir nun die weiteren Veränderungen studieren und die Haut in einem dem Abfalle des Haares nächsten Stadiums untersuchen. Für diese Untersuchungen lieferte uns die 14 Tage nach der Bestrahlıng getötete Maus wertvolles Material. Hier sind die Veränderungen je nach ihrem Grade versehieden. Mit einer eingehenden Untersuchung ist es möglich, den Konoex festzustellen.

Wir werden trachten, die verschiedenen Phasen des Prozesses, eine nach der anderen, zu verfolgen.

Die Initialhyperplasie akzentuiert sich noch in den Epithelzellen; sie dringt nach unten tief in die äußere Wurzelscheide und gelangt im Kolbenhaare bis zur Anschwellung des Bulbus und sehr nach unten in die Scheide des Haares im nicht alstiven Stande. Nachdem die Prolifera- 
tion in der Epithelscheide ihren Höhepunkt erreicht hat, beginnt in der Epidermis die regressive Phase, welche von der raschen Keratinisation und Involution der Scheidenzellen herrührt. Mit dieser Atrophie koizindiert der Ausfall des Haares.

Der Kolben, der nicht still steht in seinem Verhornungsprozesse, ist äulerst verdünnt und findet sich sehr nach oben in den von der Scheide gebildeten Gange verdrängt. In der Scheide geht der Atrophieprozeß seinem höchsten Grade entgegen; deshalb findet man in den Schnitten die Stengel an ihrem Ausgange von einer Manschette von zusammengezogenen Zellen begleitet. Da die totale Atrophie der Scheide der Austreibung des Haares vorausgegangen ist, so sehen wir die abfallenden Haare entblöbt oder fast entblößt in die oberfächlichen Schichten der Cutis (Fig. 11) eingepflanzt. Anderemale wird der rasch verhornte Kolben ausgetrieben und die atrophische Scheide (Fig. 10) bleibt leer.

Während der Atrophieprozeß in der epithelialen Scheide vor sich geht und während der Haarausfall stattfindet oder sich nähert, dauert mehr oder minder erheblich im Follikel die Hypertrophie der Bindegewebselemente fort, die dem volumsverminderten Bulbus aufsitzen. Die Erscheinungen, die hier auftreten, sind von Haar zu Haar and von Stelle zu Stelle in einem verschiedenen Grade.

In den mittleren Graden scheint der Prozeß sich nicht merklich von den normalen Verbältnissen" der follikulären Hypertrophie zu entfernen, welche den physiologischen Haarwechsel begleitet. Durch diese Hypertrophie soll nach. manchem Autor der Follikel eine doppelte und dreifache Dicke erlangen.

In den höchsten Graden wird dagegen die Bindegewebshyperplasie der Follikelwand so beträchtlich, daß man den Eindruck gewinnt, daß die Hyperplasie selbst nicht die Ursache der Atrophie der Epithelelemente des Haares ist.

In diesen Fällen bemerkt man tatsächlich, daß zwischen den Zellen der epithelialen Wurzelscheide in fortgerückter Atrophie sich Bindegewebskerue einnisten, welche die Kontinuität lockern. Im fortgeschrittenen Prozesse geschieht sogar an mancher Stelle die Verstümmelung der Wurzelscheide und es bleiben zertreut zwischen den eindringenden jungen fibro-zellulären Bindegewebsbündeln Inseln von Epithelzellen.

Anderemale, wenn zum größten Teile die Zellen der Scheidehülle zerstört $\sin d$, sehen wir um den Haarstengel, der als Fremdkörper zurückgeblieben ist, eine wirkliche kleinzellige Infiltration; manchmal auch ist die Bildung von Riesenzellen vorhanden.

Riesenzellen entstehen nicht selten aus denselben Epithelzellen, die einem Prozesse von hydropischer Anschwellung unterliegen; dies geschieht besonders, wenn die epitheliale Atrophie stürmisch einhergeht, gerade zusammen oder in der Folge der Invasion des Bindegewebselementes.

Als Ausgang der merklichen follikulären Hyperplasie, als das Haar und sein epithelialer Teil vollständig ansfielen, bleiben die von uns bei 
der Besprechung der Veränderungen der Cutis erwähnten fibrozellulären Strange zurück, welche sehr gut den Verlauf des alten Haares bezeugen and ein wertrolles Hilfsmittel bei der Untersuchung der alten Papille und zur Fesstellung der Beziehungen mit dem Haare neuer Bildung sind.

Was die Papille anbelangt, so haben wir schon früher hervorgehoben, daß die Zellgruppe, die sie darstellt, auch anzeigt, dab die Initialhyperplasie der ührigen Haarbestandteilen folgt.

Wenn wir unsere Aufmerksamkeit auf die Haut lenken, wo der Prozeß fortgeschrittener ist, so finden wir, daB das papilläre Knötchen bei seinem Emporrücken, statt hinter dem Haarbulbus zu sein, durch ein Isthmus der fibrozellulären Bündeln des bypertrophischen Follikels getrennt wurde. Es ist gut, za bemerken, daß schon normal das papillare Knötchen des Kolbenhaares sich nicht in der Richtung einer geraden Linie findet, welche die Haarachse verlängert. Dasselbe bleibt in einem mehr oder minder geschlossenen, im allgemeinen gegen die Oberfläche der Haut offenen Winkel abgelenkt. Das vom Bulbus durch den Bindegewebsisthmus getrennte Knötchen behält diese Abweichung, so daß wir, um es zu finden, gewöhnlich einige schnitte vor oder nach jener, welche die Anschwellung des Bulbuss betraf, untersuchen müssen.

Wenn wir in den Serienschnitten verschiedene sukzessive Schnitte eines Haares oder seiner Residuen untersuchen, so müssen wir immer den Vertreter der Papille finden, der immer deutlich ist, auch wenn die Atrophie des epithelialen Bulbuss fortgeschritten ist.

Gewöhnlich auch in der atrophischen Phase, welche dem Haarausfall vorangeht, ist das papilläre Knötchen wie in der Initialphase von Hyperplasie verdickt; als solches ist es unter den fibrazellularen Strängen, die den hypertrophischen und leeren Follikel darstellen (Fig. 19 u. 20), immer gut unterschieden.

Wir werden bald sehen, wie der Vertreter der Papille lange auch in der Cutis erhalten ist, welche nicht nur von jedem Haarreste und der Epidermis entblößt ist, sondern auch einem entzündlichen radiodermatitischen Prozesse unterliegt.

Die Veränderungen des Haarapparates, welche wir bis jetzt beschrieben haben, stellen die verschiedenen Phasen dar, durch welche der Prozeß geht, der zur Alıpcine führt. In unseren Untersuchungen entwickelte sich ein solcher Prozeß zwischen dem 14. und dem 20. Tage entsprechend der zentralen Bestrahlungszone. In der parazentralen Zone war der Mechanismus des Haarausfalles mit jenem in der zentralen Zone identisch; der Unterschied besteht nur darin, daß er sich langsamer entwickelt, da die betreffenden Phasen weniger rasch sind.

Außerdem ist paralell der geringen bindegewebigen Proliferation in der Cutis, auch der Haarfollikel reich an fibrozellularen Elementen; nur sehr wenig weicht er von normalen Verhältnissen ab.

Wir können inzwischen die richtigsten Veränderungen feststellen, die das Haar betreffen und zwar von ihrer ersten Erscheinung bis zum vollständigen Haarausfall. Solche sind, wir wiederholen es: infolge der 
Radiumeinwirkung entsteht zuerst eine transitorische Proliferation der epithelialen Elemente in der äußeren Scheide des Haares. Dieser Proliferation folgen die Involution und die Atrophie des ganzen Haarbulbus und der Ausfall des Haarstengels; im Haarfollikel ist eine frühzeitige Hypertrophie, die sich erhält und bis zur Austreibung des Haares fortschreitet; die in eine Gruppierung rundlicher Zellen umgewandelte Papille persistiert unverändert im ganzen Prozesse; sie wird nicht nur nicht atrophisch, sondern es scheint, daß in gewissen Momenten sie an Volumen zunehme und sich verjünge,

Nach der destruktiven Phase des Haares kommt die Regenerationsphase, die unmittelbar der ersteren dort folgt, wo kein ulcerativer entzündlicher Prozeß vorkommt; später stellt sie sich ein, wo Ulceration stattgefunden hat, nämlich nach der Vernarbung der Kontinuitätstrennung in der Haut.

Bevor wir den NeubildungsprozeB des Haares studieren, ist es gut, daß wir uns in Kürze noch mit jenen Komponenten des Haarapparates befassen, welche nach dem Haarausfalle, wir wollen sagen nach dem Ausfalle des leeren und gezogenen Follikels und des papillären Knötchens, übrig bleiben.

Die fibrösen Bündeln, welche den Follikel zusammensetzen, der zu einem fibrösen Strang reduziert ist, behalten überall ihre Individualisation bei, wo die Radiumsdermatitis sich in einem mittleren Grade entzündlicher Infiltration erhält. Nur dort, wo die Cutis von der Ulceration korrodiert wird, werden sie zerstört. In den zum Nachweise der elastischen Fasern entsprechend tingierten Schnitten erkennt man leicht die fibrösen Stränge des alten Follikels, gerade wegen der Verdichtung der elastischen Fasern, die untereinander gedrängt sind. Auf diese Tatsache haben wir bei der Besprechung der elastischen Fasern hingewiesen. Wir haben auch Fragmente von elastischer Substanz erörtert, die mit den Fasern zusammen konstatiert wurden.

Zwischeu den fibrösen Strängen des Follikels liegt das papilläre Knötchen, das immer wegen seiner Form und charakteristischen Konstitution leicht zu finden ist. In Fig. 8 sind einige solche papilläre Knötchen photographiert, die man mitten in der vou der Entzündung und Ulceration infiltrierten Outis erkennen kann; infolge der Ulceration liegen die Knötehen an der Oberfläche. In Fig. 15, 16 und 17 sieht man verschiedene Reste der papillären Knötchen, welche in der Cutis inbegriffen sind, die von einer mit schon neugebildeter Epidermis bedeckter Narbe eingenommen ist.

Es ist nicht nützlich, auf die Permanenz des Vertreters der Papille zu bestehen, weil diese Tatsache in doppelter Hinsicht von Interesse ist. Erstens beweißt sie die Resistenz der Bindegewebselemente des Haarapparates gegen die Radiumwirkung, auch wenn sie, wie in der Papille, aus einer Gruppe von Zellen statt aus fibrösem Gewebe bestehen. $Z_{w e i-}$ tens, weil sie zeigt, dab die Papille nicht nach dem Haaransfalle atro- 
phisch wird, wie einige Autoren behaupten, sondern daß sie lange Zeit auch nach dem Verschwinden des Haares individualisiert bleibt.

Ond nun untersuchen wir, wie das Haar wieder wächst.

Die alopezische Haut erlangt die Haare durch den Zusammenlauf zweier verschiedener Prozesse, und zwar des normalen Prozesses im extrauterinen Leben, das charakteristisch ist für den physiologischen Haarwechsel, und des dem foetalea Leben eigenen embryologischen Prozesses. Der erste Prozeß ist ein wirklicher Regenerationsprozeb durch Substitution des alten Haares durch ein neues, dessen Bildung aus einem Teile von jenem entspringt. Der zweite ist ein NeubildungsprozeB, weil das Haar unabhängig von einem praexistierenden und in direkter Weise an der Epidermis sich bildet.

In der seit 14 Tagen bestrahlten Haut sehen wir neben dem vorherrschenden Phänomen, dem Haarausfalle, der schon eingetreten ist oder bald eintritt, auch die ersten Versuche einer Regeneration des Haares selbst. Bei der Untersuchung verschiedener Schnitte werden hie und da in der Cutis Stränge oder Reihen von jungen Epithelzellen deutlich. Wenn wir aufmerksam diese Zellreihen untersuchen (Fig. 21, 22, 23), so finden wir im Überflusse die karyokinetischen Figuren und in den Serienschnitten sehen wir, wie diese Zellreihen voll sind; sie bestehen gänzlich aus jungen Zellen.

Diese Zellreiben erreichen bald die Epidermis, bald bleiben sie mit ihrem obəren Ende von derselben gewissermaßen entfernt. Besonders in jenen, die die Epidermis noch nicht erreicht haben, ist es leicht, zu sehen, wie ihre Zellen direkt in die Zellen des tieferen Teiles der änBeren Epithelscheide oder in jene des unteren Poles der Bulbusanschwellung des seinem Ausfalle entgegengehenden Haares hinübergehen. In der Tiefe stehen dieselben Zellreiben in unmittelbarer Beziehung mit dem rom alten Haare zurückgelassenen papillaren Knötchen; sie überschreiten die fibrösen Stränge, die es umgeben, und umhüllen das papilläre Knötchen selbst. Zn gleicher Zeit entsteht in der Linie der Einbuchtung, die diese Papille aufnimmt, eine Reihe von zylindrisch aussehenden Zellen mit häufigen Mitosen, so daß es als eine Matrixlage erscheint.

Wenn wir in weiterer Entwicklung diese Haaranlage untersuchen, so sehen wir, daß sich die Zellreibe bis zur Oberfläche erhebt; indem sie das alte Haar nach vorne drängt oder sich an dasselbe annähert, drängt sie die Papille noch tiefer. Bei der unteren Anschwellung bildet sich eine Gruppe von Keimzellen; von dieser differenziert sich eine Art Zwiebel und in der Folge entsteht durch Verhornung der oberfiächlichen Zellen die Spitze des Haares. Wie sich das rudimentäre Haar erhebt, wandeln sich die zentralen Zellen der Reihe, welche der keratohyalinen Degeneration unterliegen, um; sie fallen aus und bilden für das Haar ein zentrales Kanälchen und die äubere Epithelscheide. Zu gleicher Zeit differenzieren sich unten um die Generationszone des Haares die verschiedenen Schichten, welche die Cuticula und die innere Epithelscheide (Henlesche und Huxleysche Schicht) bilden. 
Wie man leicht konstatieren kann, ist die Analogie dieses Prozesses mit dem physiologischen Regenerationsprozesse des Haares eine vollständige und als solche verdient sie, hervorgehoben $\mathrm{zu}$ werden, weil sie den Nachweis liefert, daß unter bestimmten Verhältnissen die Radiumwirkung den physiologischen Prozeß selbst, statt ihn zu verhindern, unterstützt. Diese Verhältnisse scheinen in unseren Experimenten gerade in der parazentralen Zone der Bestrahlung za sein; wir können dies aus den Intersuchungen unseres Materials schließen, weil 14 Tage nur nach der Bestrahlung die Regenerationsbewegung in der genannten Zone deutlich eine akzentuiertere ist als in allen anderen Schnitten von normaler Haut; in zweiter Linie, weil schon am 26. Tage nach der Bestrahlung dasselbe Haar in einer Partie der parazentralen Zone vollständig von einem neuen sehr entwickelten Haare (Fig. 27) ersetzt ist.

Die physiologische Regeneration, welche in rascher und vollständiger Weise um das Geschwür auftritt, breitet sich noch peripher, aber in geringerer Ausdehnung und minder rasch ans, so daß wir in den vom Bestrahlungszentrum entfernten Schnitten, in verschiedenen Perioden zwischen dem 26. und 70. Tage, mit dem alten Haare gemischte Generationen des nenen Haares finden, und $\mathrm{zwar}$ in abnehmender Quantität mit der Bestrahlungszeit und der Entfernung von ihrem Zentrum.

Bevor wir zum Stadium der Neubildung des Haares übergehen, welche die Vernarbungszone des Geschwüres betrifft, wollen wir der Produktion gewisser Konglomerate von Hornsubstanz erwähnen, die sich in verschiedener Höhe in den Epithelzellreihen finden. Sie reproduzieren solche Konglomerate, die gänzlich den für gewisse Hautneubildungen (Cancroide) charakteristischen Perlen oder perlenartigen Körpern ähnlich sind. Es handelt sich um Konglomerate, die von einer konzentrisch geschichteten Hornsubstanz gebildet werden, die in einer im Epithel entstandenen Kavitãt enthalten ist. In diesem Falle glauben wir, daß die Genese dieser pathologischen Elemente einerseits sich auf die übermäßige stürmische Keratinisation an gewissen Stelien der neuen Epithelschichten, andererseits auf ein Hindernis sich beziehen, welches die Schichten in der kallösen Epidermis finden; letztere läßt äußerlich die Hornproduktion sich nicht ausbreiten. Diese Perlen tragen mit der Hyperplasie und cystischen Degeneration der Talgdrüsen und mit der Kallosität der Epidermis dazu bei, um dem Epithelgewebe den von uns schon erwähnten (Fig. 5) Metaplasiecharakter zu verleihen.

Wir kommen nun zum Neubildungsprozesseder Haare.

Zuerst bilden sich aus der unteren Fläche der Narbenepidermis Epithelknöpfe, wodurch die Epidermis mamelloniert aussieht; diese Epithelknöpfe imprimieren der Cutis eine papillare Fläche (Fig. 16). Langsam vertiefen sich diese Erhebungen in der Form von Epithelfortsätzen; in diesen unterscheiden wir rund herum eine Schichte oblungierter, palissadenförmiger Zellen, welche in dio Basalschicht der Epidermis übergehen und innerlich eine Schichte polygonaler Zellen, analog jenen des Malpighii, bilden. 
In diesen Fortsätzen bilden sich in kurzer Zeit Haare und Talgdrüsen. Die Differenzierung der Talgdrüsen tritt schnell auf und in gewissen Fällen finden wir sie schon, bevor man noch Anzeichen der Bildung des neuen Haares sieht, von einigen charakteristischen Zelien angegeben. Anderemale bemerken wir, daß die Talgdrüsen einen nenuenswerten Lntwieklungsgrad erzielt haben, als sich aus ihrem blinden Ende und aus der Schichte der Matrizzellen ein Anhang trennt, anf dem dann die Bildung des neuen Haares stattindet. In anderen Fällen sind schon deutlishe Differenzierungsgrade des neuen Haares obne Spur einer Bildung von Talgdrüsen.

Da nun nicht alle Haare mit Talgdrüsen ausgestattet sind und wir nicht wissen, ob auf dem Haare sich später Talgdrüsen entwickeln werden, ferner, da wir die Möglichkeit dieser Entwicklung durch Differenzierung der äußeren Scheide annehmen raüssen, so sind wir nicht in der Lage, mit Sicherheit zu beurteilen, ob die Entwicklung der Talgdrüse lronstant der Entwicklung des betreffenden Haares vorangeht.

Diese Frage ist übrigens von geringem Interesse; für uns genügt, hingewiesen zu haben, wie aus dem epidermalen Zellfortsatze sich Talgdrüsen und Haare entwickeln.

Der Fortsatz, aus dem das Haar entsteht, stamme derselbe direkt aus der Epidermis oder sei er nur ein sekandärer Anbang der neugebildeten Talgdrüse, beginnt seine Differenzierung in dem Momente, in dem er der Papille begegnet. Der Fortsatz wird länger und an seinem unteren Ende intraflektiert; in einer Nische (Fig. 21) wird die Papille aufgenommen; erst dann bildet sich die $Z$ wiebel, die das Rudiment des eigentlichen Haares darstellt. Die konsekutive Kanalisation des Zellfort. satzes, die Bildung der Scheiden in ihren verschiedenen Schichten und das Anwachsen des Haares gehen in der gewöhnlich jetzt bekannten Weise vor sich.

Wir haben gesagt, daß das untere Ende des Zellfortsatzes, aus dem der epitheliale Teil des neuen Haares sich bildet, die Papille erreicht und dieselbe in gewöhnlicher Weise bedeckt.

Und nun über den Ursprung der Papille des neugebildeten Haares.

Hier kommt eine viel besprochene Frage bezüglich des Haarwechsels in Betracht; es handelt sich darum, ob die Papille des neuen Haares aus der alten wiederhergestellten Papille oder durch Differenzierung ex novo aus den Zellen des Bindegewebes der Cutis sich bildet. Diese Frage ist wichtio, denn es handelt sich, ob die Papille eine Art kleines Organes darstellt, das stabil ein extra-embryonales Leben ist und ob die Cutis, respektive ein extra-embryonales Leben, die Fäbigkeit beibehält, eine Haarpapille zu bilden.

Wir können uns nicht in eine gründliche Diskussion einlassen, wir beschränken uns darauf, die Untersuchungsresultate unseres Materiales auseinanderzusetzen.

Vor allem wiederholen wir, was wir schon behauptet haben; die Reste der Papille des zerstörten Haares, welche in der Cutis als rund- 
liche, von den fibrösen Resten des Follkels umgebene Knötchen erkennbar sind, finden sich in den verschiedenen Zeitperioden nach dem Haarausfall und der Bildung des Geschwüres bis zur vollständigen Vernarbung (Fig. 12, 13,14, 15, 16, 17, 21, 22, 23, 24, 25 und 26) der Radiumdermatitis.

Es ist nichts mehr notwendig, um die Resistenz und das Überleben des die Papille darstellenden Knötchens nachzuw eisen. Mann kann auch nicht den Verdacht haben, daB es sich um nengebildete Zellknötchen bandelt, denn die Anwesenheit um dieselben von Resten des fibrösen Gewebes des Follikels und speziell der elastischen Fasern mit ihrem charakteristischen Aussehen, läßt eine solche Hypothese ausschließen. So ist es auch gewiß, daß früher oder später auf diesen papillären Knötchen ein Epithelstrang kommt, aus denen sich dann (Fig. 25) ein neues Haar bildet.

Infolgedessen können wir behaupten, daß auch die Haare neuer Bildung sich einer alten Papille anpassen. In gewissen Narbenstücken zwischen den fibrösen Resten des alten Follikels, welches gut erhalten ist und neben den der M. arrector pili vorkommt, der auch gut erhalten ist, gewinnen wir bei der Untersuchung den Eindruck, als ob gerade dem fibrösen Bündel der Weg des epidermoidalen (Fig. 26) Fortsatzes folge. Wir fragen, ob man nicht annehme könne, daß der aus dem papillaren Knötchen ausgehende fibröse Strang eine Art Traktion auf die Epidermis ausübe und die Verlängerung, die das neue Haar bilden wird, bedinge. Diese Hypothese ist nicht gänzlich gewagt, wenn man bedenkt, daß den Fasern des funktionierenden Follikels die Fähigkeit zugeschrieben wird, sich sowohl im Sinne der Länge als auch der Breite des Follikels selbst zu kontrahieren; dies würde nach $\mathrm{Eb}$ er der Ausgangspunkt der Aufhebung des Haares und seiner nachfolgenden Veränderungen bis zum Wechsel sein. Übrigens muß man wenigstens für die Fasern des M. arrect. pili die Fakultät einer Traktion, denn infolge der Vernarbung liegen die Fasern selbst auf die bindegewebigen und elastischen Fasern des alten Follikels; so läßt sich die Hypothese wenigstens bezüglich des glatten Muskels halten. Nicht in allen Fällen kann man eine Art Traktion im obigen Sinne annehmen, denn einigen Epithelsträngen gehen nicht voran, noch werden sie davon begleitet, deutliche fibröse Bündel, die in der Richtung der Stränge selbst verlaufen.

Es sind Fälle, in denen es nicht deutlich ist, ob die Papille des neuen Haares sich aus den Resten einer alten bilde. In diesen können wir die Möglichkeit einer Bildung der Papille ex novo durch Differenzierung der Bindegewebszellen der Cutis nicht in Abrede stellen. Wir können auch den Verdacht haben, daß manches altes Zellknötchen aurch die entzündliche Infiltration der Radiumdermatitis dermaßen gelocktert sein kana, daß die Elemente zwischen dem Granulationsgewebe zerstrent ljegen und aus denselben sich eine neue Papille bilde.

Aus unseren Untersuchungen können wir den Schlub ziehen, daß die Zellen der Haarpapille im extra-embryonalen Leben eine eigene 
Funktion angenommen haben: sie sind desbalb als differenzierte Zellen anzusehen.

Andernfalls könnte man sich nicht erklären, warum das Regenerationshaar sich der alten Papille beđiene; man würde nicht erklären können, warum das Haar never Bildung auf ein altes papilläres Knötchen wachse, und zwar einige Monate, nachdem das papilläre Knötchen isoliert und ohne Funktion ist; um so weniger könnte man erklären, warum jene Gruppe von Zellen bindegewebigen Ursprunges so lange individualisiert der Ausbreitung des entzündlichen Prozesses wiederstehen muß.

Nachdem wir die Veränderungen detailliert beschrieben haben, wiederholen wir dieselben folgendermassen:

Entsprechend der zentralen Zone der Bestrahlung finden sich in den ersten Tagen zwischen den Zellen der äußeren Scheide Proliferationsbewegungen. Später tritt aber in den ganzen epithelialen Teil des Haares ein AtrophieprozeB ein, der zum Haarausfalle (Alopecie) selbst führt; dies geschieht zwischen dem 14. und 20. Tage nach der Bestrablung.

Die Atrophie betrifft aussehlieBlich den Bulbus. Der Follikel dagegen wird atrophisch und, vom Haare entleert, bildet er sich in einen mehr oder minder beträchtlichen fibrozellularen Strang um, der die Lage des ausgefallenen Haares anzeigt.

Die Papille, in eine Gruppe rundlicher Zellen umgewandelt, resistiert und erhält sich unversehrt in der Cutis, auch wenn die entzündliche Infiltration merklich ist.

In der parazentralen Zone siebt man einige Tage nach der Bestrahlung je nach den Fällen entweder eine deutliche Beschleunigung im physiologischen Haarwechsel oder eine Entleerung der Scheide durch Trennung des atrophisierten Stengels von der Wurzel. Sowohl die eine wie die andere Erscheinung tragen zur einfachen Alopecie von kurzer Dauer bei; sowohl in dem einen wie in dem anderen Falle verliert man nicht gänzlich das epitheliale Element; von demselben bleibt immer noch so viel zurück, als zur Wiederbildung des Haares nötig ist. Der Follikel und die Papille in dieser Zone erleiden keine merklichen Veränderungen.

Die Neubildung des Haares findet in zweifacher Weise statt; entweder durch Regeneration oder durch Neubildung. Die Regeneration, die nur in der parazentralen Zone stattfindet, geht aus den übrig gebliebenen Elementen des Bulbus oder der äußeren Epithelscheide des alten Haares hervor. Sie beginnt einige Tage nach der Bestrahlung und nimmt rasch zu, so daß bei der mikroskopischen Untersuchung der am 26. Tage nach der Bestrahlung entnommenen Haut wir schon um das Geschwür eine neue Generation von Haaren in fortgeschrittener Entwicklung sehen. Diese Regeneration wechselt zwei Monate in der parazentralen Zone mit dem Haarausfall, bis gegen Ende des dritten Monates von der Bestrahlung das Haar dort gänzlich renoviert ist.

Für die zentrale Zone, d. i. den Bezirk des Geschwüres, ist die Neubildung des Haares eigen. Sie geschieht nach dem embryonalen 
Prozesse durch Fortsätze der Narbenepidermis, die sich in die Cutis vertiefen und langsam das Haar hervorbringen. Sowohl bei der Regeneration als auch bei der Neubildung des Haares paßt sich gewöhnlich die alte Papille dem neuen Haare an.

\section{Talgdrüsen.}

Bei der Maus bilden die Talgdrüsen kleine Epithelschläuche, die in enger Verbindung mil dem Haarapparate stehen, an den sie sich ungefähr in der Mitte seines Verlaufes durch die Cutis anlegen. Von länglicher eiförmiger Form haben sie zwei Pole, deren unterer den geschlossenen Boden der Drüse bildet, während der obere sich mit einem kurzen Schaltstücke in den Haarkanal öfnet, wo die Drüsen ibre Sekretionsprodukte ergießen. Meistens bilden zwei Lappen den Talgdrüsenapparat; manchesmal findet sich aber nur ein Lappen. Nicht alle Haare sind mit Talgdrüsen versehen; auch sind die Drüsen nicht in gleichem Maße über die verschiedenen Bezirke der Haut verteilt; so kommt es, daß man bei der mikroskopischen. Untersuchung einerseits an Talgdrüsen sehr reiche Schnitte trifft, auf anderen Schnitten dagegen nur wenige Exemplare oder überhaupt keine sieht. Die Zellen der Talgdrüsen der Maus haben die gleichen Charaktere und Eigenschaften, wie sie den Talgdrüsen im allgemeinen zukommen.

Während man bei der makroskopischen Betrachtung der bestrahlten Haut niemals irgend etwas an den Drüsen selbst oder ihrer Funktion bemerkt, sind bei der mikroskopischen Untersuchung dagegen die Befunde sehr interessant.

Schon am fünften Tage nach der Bestrahlung - und von da an in immer stärkerem Maße - findet man die Talgdrüsen erheblich vergrößert. Besonders ihr Querdurehmesser nimmt zu, wenngleich auch im Längsdurchmesser ein Wachstum deutlich ist. Untersucht man aufmerksam die Drüsen, so erkennt man leicht die gesteigerte Aktivität sowohl der Sekretion als auch der Proliferation. In der Nähe der Einmündung in den Haarkanal finden sich reichliche Talgmassen; die oberflächlichen Zellen befincien sich in weiter Ausdehnung im Zustande der speziellen fettigen Involution. Die tiefen Zellen zeigen sebr ausgesprochene Konturen, reichliches Protoplasma und einen großen blassen Kern. Nach dem Drüsenboden zu haben die Zellen entschieden jungen Charakter und es finden sich unter ihnen zahlreiche karyokinetische Teilungsfiguren (Fig. 25); in dieser Weise bilden sich 4-5mal größere runde Schiäuche als die normalen,

In einer mehr fortgeschrittenen Phase sind die Talgdrüsen dort, wo die Erosion der Cutis stattgefunden hat, verschwunden; wir finden sie aber um das Geschwür immer sehr reichlich. In der seit 26 Tagen bestrahlten Haut finden wir, da das Geschwür vollständig gebildet ist, in der parazentralen Zone und in unmittelbarer Nähe der Kontinuitätstrennung, in Fülle die verdickten Talgdrüsen. Aber während einige der- 
selben die cbarakteristische Drüsensubstanz beibehalten, wandeln sich dagegen andere in Ampulten oder cystische Kavitüten infolge einer progressiven Atrophie der eigentlichen Zellen um, welche langsam sich in eine Masse ron Talgsubstanz auflösen. Bei der Serienuntersuchung ist es leicht; sich zu überzeugen, daB einige dieser Kavitäten in Verbindung mit der äuBeren Fläche der Epidermis bleíben, während dagegen andere wirklich geschlossene Cysten bilden, welche von einer Wand begrenzt werden, die aus einer Reihe von stark abgeflachten und von der angehäuften Talgmasse zerquetschten Zellen bestehen.

Es handelt sich hier deutlich um den Ausdruck der Drüsenatrophie, aber zu ihrer Bildung trägt außer der primären Wirkung des Radiums auf die Zellen, anch in nicht zu vernachlässigender Weise eine sekundäre mechanische Wirkung bei dureh Zerstörung des Drüsenhalses, sei es durch die hyperplastische und kallöse Epidermis, sei es durch das Bindegewebe der Cutis. Infolgedessen häuft sich das Drüsensekret, das den Ausgang nach außen verspert findet, im Innern der Drüse und wirkt direkt durch den inneren Druck schädigend auf die Drüsenzellen.

Diese Atrophie aber beschränkt sich auf eine gewisse Zahl von Talgdrüsen und besonders auf jene, welche unmittelbar das Geschwür umgeben. Neben ihnen sind andere hypertrophische Drüsen, welche ihre charakteristische Struktur beibehalten.

Außerdem mischen sich darunter regenerierte Drüsen, die ihrerseits noch ein beträchtliches Volumen annehmen. Diese neuen Drüsen bilden sich aus den Epithelzęllsträngen, aus denen die Haare herrühren, in der von uns beschriebenen Weise.

Wir finden daher in einer gewissen Zeitperiode nach der Bestrahlung und in gereiften Hautpartien eine Fülle von Drüsenelementen, sei es in der Form aktiver und hypertrophischer Drüsen, sei es in der Form von Talgcysten. Fig. 5 reproduziert diese Situation, die wir schon definiert haben, eine Metaplasieform der epithelialen Elemente.

In größerer Entfernung von der Bestrahlung - 45-70 Tage n. B. finden wir noch hypertrophische Talgdrüsen, ebenso wie einige cystische Bilduugen; aber es ist schwer zu sagen, ob mehr alte Elemente als neugebildete vorkommen, denn in dieser Epoche ist die Regeneration und die Neubildung auch der Talgdrüsen aktiv.

Die Neubildung von Talgdrüsen beginnt frühzeitig aus den Eipithelzellsträngen, die sich in die Cutis vertiefen, stammen dieselben sei es aus Resten des alten Haares, sei es aus Fortsätzen der Narbenepidermis.

In der parazentralen Zone finden wir schon am 20. Tage seit dem Beginne der Bestrahlung, daß in den Épithelsträngen sich deutlich einige Zellen differenzieren, welche voluminöser werden und ein sehr gekörntes Protoplasma erlangen, das sich bald in Talgsulstanz umwandelt.

In der zentralen Zone beginnt die Neubildung aus den Epithelsträngen, sobald dieselben eine gewisse Entwicklung erzielt haben. Wir haben schon die Beziehungen besprochen, die zwischen der Entwicklung 
der Talydrüsen und jener des Haares herrschen und es ist nicht nötig, auf dieses Gebiet noch einmal zu greifen.

Die neven Drüsen nehmen rasch an Volumen zu und erlangen das Aussehen der alten hypertrophischen Drüsen der parazentraleu Zone. Zwischen den Talgdrüsen neuer Bildung stellt man cystische Dilatationen fest, wahrscheinlich mit demselben Mechanismus, den wir für die von alten Drüsen gebildeten Talgcystea aufgestellt haben, vielleicht mit dem kausalen Unterschiede, daß, während in der parazentralen Zone die Proliferation noch dem Radium zuzuschreiben ist, im Narbengewebe dagegen wahrscheinlicher ist, die Hyperplasie und die cystische Umbildung dem Wachstume der Gewebe never Bildung zuzuschreiben ist.

Schließiich erwähnen wir eine Besonderheit, die wir in den Talgdrüsen gefunden haben, die zu jener Partie gehörten, wo das Geschwür war und die schon seit langer Zeit in Vernarbung überging. Die Talgdrüsen, die wir in der zehn Monaten nach der Bestrahlung getöteten Maus finden, sind nicht einlappig, wie gewöhnlich, sondern (Fig. 18) mehrlappig. Es ist wahrscheinlich, daß dies eine Folge der primären Entwicklungsfülle ist und daß mit ihr in einiger Beziehung die beständige Spärlichkeit der Haare stehe, sodaß die von den Haaren nicht resorpierte Ernährung zu Gunsten der Talgdrüsen verwendet wird, welche hypertrophisch sich aus einfachen in mehrlappige umwandeln.

Wenn wir die durch das Radium in den Talgdrüsen hervorgerufenen Veränderungen wiederholen, so haben wir als erste Reaktion eine Hyperplasie der Drüsenelemente mit Verdickung des Organs and Hypersekretion von Talgsubstanz gesehen. An einer gewiæsen Stelle hört die Hyperplasie auf und die talgige Degeneration geht weiter, sodaß langsam die Urüsen sich in Cysten umbilden, bald geöffnet, wenn der relative Ausführungsgang offen bleibt, bald geschlossen, wenn der Hals entweder durch die kallöse Epidermis oder vom infiltrierten Bindegewebe zerstört wird. Die cystische Umbildung stellt die Atrophie der Talgdrüse dar.

Die Neubildung der Talgdrüsen geht reichlich von den Epithelsträngen hervor, aus denen sich das Haar, sei es durch Regeneration, sei es durch Neubildung, entwickelt.

\section{Schlußbetrachtungen.}

Wir wiederholen nun in kurzer Synthese die Resultate unserer Experimente und erklären die wichtigsten von uns beobachteten Tatsachen.

Mit der Einrichtung unserer Experimente konnten wir die verschiedenen durch die Radiumwirkung auf das Hautgewebe der Maus hervorgerufenen Veränderungen in Beziehung mit der verschiedenen Intensität der Strahlen selbst studieren. 
Es ist nitzlich, anch bei unserer Wiederholung zuerst die Veränderungen der mehr bestrahlten Zone (zentrale Bestrahlungszone) und dann jene der mäßig bestrahlten Zone (parazentrale Zone) in Erwägung zu ziehen.

Nachdem einmal schematisch die Resultate der Experimente fixiert sind, werden wir über das Gesamte einen Rückblick. werfen, um daraus eine Erklärung bezüglich des Wirkungsmechanismus des Radiums zu gewinnen.

Intensive Bestrahlung. Bei der direkten Untersuchung der am meisten vom Radium getroffenen Zone haben wir in den ersten zwei Wochen eine Desquamation der Epidermis gesehen, während der dritten Woche den Ausfall der Epidermis und der Haare und die Bildung eines Geschwüres von langer Dauer.

Bei der mikroskopischen Untersuchung fanden wir.

Bezüglich der epithelialen Gewebe (Epidermis, Haar, Talgdrüse) folgten die Veränderungen zwei getrennten Pbasen; in der ersten Zeit nämlich (3.-10. Tag) bemerkte man in allen epithelialen Geweben eine Zellproliferation; später (10.-20. Tag) eine progressive Atrophie der Elemente in denselben Geweben bis zu ihrem vollständigen Schwunde.

Als Ausdruck der Zellproliferation fanden wir: in der Epidermis Vermehrung und konsekutive Schichtung der Epithelzellen; im Haare Wiederverjüngung und Vermehrung der Zellen der äußeren epithelialen Scheide, überdies an gewissen Stellen eine Beschleunigung für den Haarwechsel; in den Talgdrüsen Vermehrung der Drüsenzellen und konsekutive Verdickung und Hypersekretion der Drüsen.

Als Ausdruck der Atrophie sahen wir:

In der Epidermis rasche keratohyaline Degeneration der Epithelzellen und konsekutive Hyperkeratose, dann vollständige Trennung der Epidermis; im Haare im oberen Teile der äußeren epithelialen Scheide keratohyaline Degeneration, rapide Keratinisation des Bulbus, Austreibung des Haares und Schwund eines jeden Bulbusrestes; in den Talgdrüsen Vermehrung der Talgdegeneration der Zellen und zum Teile cystische Umwandlung der Drüsen selbst.

Bezüglich des Bindegewebes haben wir eine zellige Proliferation gesehen, die besonders das Bindegewebe der Cutis und 
der Wandung des Follikels betraf; diese Proliferation war stabil insoferne zum Unterschiede der Epithelgewebe, diese Bindegewebe im Zustande der Hyperplasie auch mit der Einstellung des ulcerösen Prozesses blieben.

Als Ausdruck der Bindegewebshyperplasie fanden wir: in der eigentlichen Cutis, beginnend rom 5. Tage nach der Bestrahlung eine Vermehrung der fixen Zellen und eine Infiltration der Wanderzellen; im Haarfollikel dieselbe Vermebrung an Zellen und elastischen Fasern und die Umbildung des Follikels in einen fibrozellulären Strang.

Betreffs der Haarpapille können wir sagen, daß dieselbe durch die Wirkung des Radiums keinen Schaden erleidet; sie zeigte eine wesentliche Resistenz nicht nur gegen das Radium an und für sich, sondern auch gegen den sekundären entzündlichen Prozeß der Dermatitis.

Von den übrigen Elementen und Geweben der Haut (elastische Fasern, Musculi arrectores pilorum und Haarbalg) können wir sagen, da $\beta$ sie sich passiv verhalten; sie waren alteriert respektive zerstört nur in sekundärer Linie, nicht durch die direkte Wirkung des Radiums, sondern durch den Effekt des ulcerativen Prozesses.

Die Blut- und Lymphgefäße erweiterten sich frühzeitig; sie waren dilatiert und kamen überall reichlich vor, wo der Blutanspruch groß und Säftewechsel ein aktiver war, sei es durch die größere Aktivität der Proliferation sei es durch die Entwicklung des entzündlichen Prozesses. Wir haben aber niemals spezielie Veränderungen in ihren Wandungen - nicht einmal in der Intima - konstatiert, die primär der Radiumwirkung zuzuschreiben wären und solche, die für die Entwicklung der Hautreränderungen der Hautgewebe wichtig gewesen wären.

Mäßige Bestrahlung. - Die bei der direkten Untersuchung der parazentralen Zone sichtbaren Tatsachen waren wesentlich der Haarausfall ohne Exkoriation (einfache Alopecie), ein rugöses Aussehen und eine kleinschuppige Desquamation der Epidermis.

Bei der mikroskopischen Untersuchung fanden wir wesentlich eine gesteigerte Proliferation in allen epithelialen Schichten, nämlich Schichtung der Epidermis, beschleunigter Haarausfall und volle Entwicklung der Zellfortsätze, welche zur Bildung 
der neuen Haare bestimmt sind; überdies Hypertrophie and cystische Erweiterung der Talgdrüsen; ein Komplex ron Tatsachen, die in ihrer größten Akzentuierung dem Epithelgewebe den Charakter einer Metaplasie (Fig. 5) verliehen.

Im Bindegewebe der Cutis haben wir kaum eine zellige Infiltration von Realtion um das entzündliche Gewebe der Dermatitis ulcerosa in der zentralen Bestrahlungszone bemerkt. Auch im Haarfollikel spärliche Hypertrophie. Dilatierte Gefäße in einer gewissen Strecke und vom benachbarten entzündlichen ulcerösen Prozeß abhängig. Die übrigen Gewebe unversehrt.

Wenn wir die Veränderungen in der meist bestrablten Zone mit jenen in der minder bestrahlten Zone vergleichen, so erscheint deutlich wie diese sich jenen in ihrer ersten Phase supraponierten, die durch die Hyperplasie des epithelialen Gewebes charakterisiert ist. Eine Differenz besteht aber in der zweiten Phase (Atrophie), indem diese, wo die Wirkung des Radiums fehlte, weniger intensiv war; die Restitutio ad integrum trat durch ein Verschwinden der primären Hyperplasie ein.

Im ganzen sind deshalb im pathologisch-physiologischen Prozesse zwei Phasen zu verwerten, die Phase der Hyperplasie, beiden Zonen gemeinschaftlich und die Phase der Atrophie, die der intensiv bestrahlten Zone eigen ist.

Bezüglich der Hyperplasie des Epithelgewebes in der zentralen Bestrablungszone besteht kein Zweifel, daß sie ausschließlich und primär durch die Radiumwirkung bedingt ist, da sonst keine andere Ursache annehmbar erscheint. Die Frweiterung der Gefäße und die größere Blutfülle, welche die epitheliale Hyperplasie begleiten, können nicht als bedingende Ursache der letzteren angesehen werden; sie sind eine Folge oder eine Konkomitierung.

Aber die epitheliale Hyperplasie der parazentralen Bestrahlungszone ist ein Effekt der Radiumwirkung?

In der Verwertung derselben müssen wir vor allem einem Präjudiz Rechnung tragen, das sich auf die Tatsache bezieht, dah die epitheliale Hyperplasie sich in einer, der durch die radiodermatitische Ulceration charakterisierte Kontinuitätstrennung nahen Zone entwickelte. Wir wissen nun, daß in der Epidermis in der nächsten Nähe von Substanzverlusten physio- 
logisch Proliferationserscheinungen auftreten, welche die Verluste reparieren; es entsteht sekundär nach der Kontinuitätstrennung eine reaktive Hyperplasie. Dieser Faktor kommt auch deutlich in der Epidermis, in der Umgebung des durch das Radium hervorgerufenen Geschwüres, in Betracht und hat seinen Anteil bei der Bildung der kallösen Epidermis, Aber nur einen Teil, und nicht den größeren, können wir ihm zuschreiben; und zwar im wesentlichen aus zwei Gründen; vor allem, weil wir deutlich die epitheliale Hyperplasie in der parazentralen Zone sahen, als das Geschwür in der zentralen Zone (letzte Periode der atrophischen Phase) noch nicht gebildet war; es war nicht einmal physiologisch die Reparation notwendig; in zweiter Linie, weil wir die epidermale Hypertrophie in einer Entfernung ( $1 \mathrm{~cm}$ und mehr) vom Geschwürrande sahen, zu dem die sekundäre reaktive oder Reparationshyperplasie nicht gelangen kann. Wir haben uns dessen mit einem Kontrollexperimente überzeugt, indem wir die Extension und den Grad der Reparationshyperplasie an der Haut einer Maus studierten, an welcher wir das Geschwür mit dem glühenden Eisen hervorriefen.

Wir halten uns für ermächtigt, die epitheliale Hyperplasie der mäBig bestrahlten Zone zum gröBten Teile der direkten Wirkung des Radiums zuzuschreiben, indem wir so die Analogie mit der Hyperplasie, die in der ersten Zeit in der zentralen Bestrablungszone auftritt, feststellen.

Wir fanden deutlich die primäre Hyperplasie in direkter Abhängigkeit von der Radiumwirkung in dem Verhalten des Haarsystems. Im Haare sehen wir gerade entsprechend dem der Ulceration benachbarten Bezirke eine beträchtliche Aktivierung des Haarwechselprozesses, der in solchem Grade nirgends, weder in der gesunden Haut noch in jener ron anderen Mäusen, gefunden wurde.

Überdies fanden wir einige Tage nach der Bildung des Geschwüres (26 T. n. B.) in der ihm benachbarten Zone eine vollständige Erneuerung des Haares, in dem Sinne, daß das alte gänzlich oder fast gänzlich (einfache Alopecie) ausgefallen war; an seiner Stelle wuchs das neue auf den Resten des alten. Wir sind nicht in der Lage, festzustellen, wie viel Zeit das Haar 
im Wechsel braucht, um auszufallen und sich zu erneuern; jedenfalls ist es außergewöhnlich, daß dieser Prozeß innerhalb 20-26 Tagen stattfindet.

Aus diesen Gründen sehen wir in dem Verhalten des Haares einen Beweis für die hyperplasierende Wirkung des Radiums.

Dieselbe zeigten anch die Talgdrüsen, sei es in der zentralen Zone (erste Phase), sei es in der parazentralen Zone.

Wir können daher die erste Phase der Hautveränderungen folgend fassen:

Das Radium bringt in den Epithelgeweben der Haut der Maus eine Proliferation der Zellen hervor, welcher eine Schichtung der Epidermis, eine Beschleunigung des Haarwechsels und eine Hypertrophie der Talgdrïsen folgen.

Untersuchen wir nun die zweite Phase des Prozesses, die Phase der Atrophie.

Diese bildet im vulgären Sinne den essentiellen Ausdruck der Radiumwirkung im Gegensatze, wie es scheint, zur Hypertrophie. Es scheint im Gegensatze, wenn man die Tatsachen der Hypertrophie und der Atrophie isoliert studiert; aber es geht die Folge daraus, wenn man die verschiedenen Momente des pathologischen Prozesses koordiniert und verfolgt, so wie wir es taten.

Und wirklich, wenn man langsam die Veränderungen in der Epidermis verfolgt, so haben wir gesehen, wie auch frühzeitig an der Seite der Hyperplasie der Zellen sich auch ein ProzeB rascher Umbildung derselben sich akzentuiert, welche durch die keratohyaline Degeneration und durch die Bildung von Hornsubstanz charakterisiert ist. Während die Zellhyperplasie in den ersten Tagen (3.-10. T. n. B.) die Keratinisation überragt oder dieselbe kontrabilanziert, geschieht nach einiger Zeit, daß diese jene überragt mit dem Ausgange in der Phase der Hyperkeratose, welcher eine vollständige Atrophie folgt. Aber die keratohyaline Degeneration und die finale Umwandlung in Hornsubstanz stellten den physiologischen Involutionsprozeß der Epidermiszellen dar. Infolgedessen bei dem Übergange von der Hyperplasie zur Atrophie finden wir einfach eine Vermehrung des normalen Involutionsprozesses der Epidermiszellen. In dieser Weise ist die Kontinuität in den Effekten der Radiumwirkung geklärt. 
Wir können eine wichtige Tatsache behaupten, nämlich, daß der Initialhyperplasie der Epithelgewebe die Zellatrophie folgt; aber in dieser tritt keine spezielle und spezifische Erscheinung des Radiums dazwischen, sondern einfach ein stürmisches Abfallen der physiologischen Involution der Epithelzellen.

Die Tatsache, die nach uns das Punctum saliens der Radiumwirkung ist, richtet eine von Apolant bezüglich der experimentellen Karzinome aufgestellte Hypothese wieder auf, nach welcher diese Neubildungen durch graduelle Resorption ohne wirkliche Tatsachen von Necrobiose verschwinden.

Die Tatsachen, welche in den Talgdrüsen stattfanden, entsprechen denjenigen in der Fpidermis. Auch die Talgdrüsen bestehen aus Zellen, welche normal sich fortgesetzt erneuern infolge einer speziellen Involution der alten; infolgedessen stellt die übermäßige Talgproduktion, welche der Initialhyperplasie folgt, das Übermaß eines physiologischen Prozesses dar, der bis zur vollstäsdigen Steatose der Drüse und nachfolgenden cystischen Umbildung durch die partielle oder totale Retension des Sekrets gelangt, je nach dem von uns beschriebenen Mechanismus.

Im Huare ist der AtrophieprozeB nicht so einfach. Die Proliferation in den Epithelzellen des Bulbus ist wenig beachtenswert und flüchtig. Es ist anzunehmen, daß ihre Atrophie direkt durch die Radiumwirkung bedingt wird, wenigstens in gewissen Fällen, in denen eine andere Ursache für die Atrophie nicht zu finden ist. Jedenfalls ist es vom Vorteile, hervorzuheben, wie auch bei der Atrophie der Epithelzellen des Bulbus Erscheinungen der normalen Involution mit stürmischem Verlaufe konstatiert werden.

Aber meistens entwickeln sich um die Epithelzellen des Bulbus Tatsachen, durch welche wir bezïglich der epithelialen Atrophie zu anderen Erklärungen Zuflucht nehmen. Wir haben tatsächlich konstatiert, daß der Haarfollikel schon seit den ersten Tagen nach der Bestrahlung reich an Bindegewebszellen wird und sich hypertrophiert. Wir fragen: kann die Hypertrophie des Follikels die Atrophie der Bulbuselemente beeinflußen? 
- Bei der Untersuchung unseres Materiales haben wir manchmal konstatiert, da $\beta$ die Proliferation der Bindegewebszellen des Follikels eine solche war, daß sie die epitheliale Scheide und den Bulbusgrund invadierte und lockerte, so daß die Epithelzellen zerstört und zerstreut oder zu kleinen Zapfen reduziert wurden

Da man in diesen Fällen auch die Nekrobiose (Vakuolisation des Protoplasma, Pyknose und Chromatolyse des Kernes) sah, kann man keinen Zweifel haben, daß die Atrophie des Bulbus der Hyperplasie des Bindegewebes des Follikels sekundär sei. Infolgedessen können wir wenigstens zum Teile annehmen, daß die Hyperplasie des Bindegewebes zur epithelialen Atrophie beiträgt.

Beziiglich der Beziehungen zwischen epithelialer Atrophie und bindegewebiger Hypertrophie kann man die Frage so stellen: Würde nicht die Hypertrophie des Follikels der Atrophie des Bulbus sekundär sein?

Auch diese Möglichkeit können wir nicht ohne weiters in Abrede stellen, besonders für jene Fälle, in denen die bindegewebige Hyperplasie nicht einen invadierenden Charakter hat, sondern die Epithelatrophie einfach zl ersetzen oder zu kompensieren scheint. Gewiß müssen wir annehmen, daß höchstens die bindegewebige Hypertrophie von der epithelialen Atrophie begünstigt und nicht bedingt ist, als Hypertrophie ex vacuo, da die Proliferation des Bindegewebes zweifellos der primären Wirkung des Radiums zuzuschreiben ist, wie aus den ersten Stadien der Veränderungen (5 T. n. d. B.) hervorgeht, wo wir Cutis und Follikel reich an proliferierenden Bindegewebszellen sahen, wenn der Bulbus des Haares statt in Atrophie sich in transitorischer Hypertrophie fand. Fügen wir hinzu, daß die Proliferation und die bindegewebige Infiltration in der Cutis und im Haarfollikel primär auftreten, auch in Beziehung zur Epidermis, daß sie sich einstellen seit der Zeit, wo die Epidermis hyperplastisch ist und infolgedessen man auf eine entzündliche Einwirkung von äußeren Agentia wegen fehlenden Schutzes der Epidermis nicht denken kann. Wir stellen diese Tatsachen der primären bindegewebigen Hypertrophie folgendermaßen fest: 
Das Radium ruft in der Cutis und im Baarfollikel der Haut der Maus einen Proliferationsprozeß der Zellen und eine Hyperplasie derselben hervor.

Nachdem die wesentlichen Punkte der Radiumwirkung auf das Epithel und Bindegewebe festgestellt sind und nachdem wir unsere Betrachtungen über die Beziehungen zwischen Epithel und Bindegewebe in Bezug auf das Haar auseinandergesetzt haben, können wir die Wirkung des Radiums auf das Haar folgendermaßen wiederholen.

Infolge der Wirkung des Radiums auf die Haut der Maus tritt durch vollständige Atrophie des Bulbus Haarausfall auf; die Atrophie ist zum Teile der eigenen Involution der epithelialen Elemente des Bulbus und zum Teile der Hypertrophie des Follikels und der Atrophie der Epithelzellen zuzuschreiben; beide Prozesse sind die Folgen der direkten Wirkung des Radiums.

Wir heben hier hervor, was wir schon erwähnt haben, daß die jetzige herrschende Meinung über die Wirkung des Radiums auf die Gewebe die Effekte, die man experimentell oder therapeutisch bei der Radiumapplikation beobachtet, einem dystrophisch-necrobiotischen Prozesse zuschreibt. Die deletäre Wirkung entsteht durch eine Störung in der Ernährung und dem molekularen Gefüge der Zellen, sei es primär durch eine direkte physio-chemische Wirkung auf das Zellprotoplasma, sei es sekundär durch Veränderungen in den Gefäßen und der Ernährung.

Die von uns beobachteten: mit einander verbundenen Tatsachen, eine abhängig von der anderen, würden schlecht interpretiert werden, wenn man einfach eine Störung im Metabolismus der Zellen und umso weniger eine Veränderung im molekularen Gefüge, z. B. durch Dekomposition des Lecithins nach der Theorie von Schwarz und Werner annehmen würde.

Wir haben wohl in unseren Experimenten die Atrophie und die epitheliale Zerstörung dort, wo die Wirkung des Radiums eine intensive war, gesehen, aber beim Studium der Atrophie haben wir konstatiert, daß derselben eine Phase von Hypertrophie der relativen Gewebe vorangeht. Wir konnten 
dann die Korrelation zwischen der Hypertrophie und Atrophie feststellen und haben gesehen, wie diese nichts anceres ist, als die Fortsetzung oder Folge derseiben. Überdies haben wir gesehen, da die Radiumprirkung nicht intensiv war, daß die Veränderung der epithelialen Gewebe sich auf die Phase der Hyperplasie beschränkt. Aus dem ganzen geht hervor, daB die von uns bestrahlten Zellagregaten sich statt der molekularen Veränderungen nach der Lehre passiv zu verhalten, aktiv reagierten mit übermäßigen vitalen (abnorme Proliferation der Zellen) Manifestationen.

Infolgedessen scheint uns am meisten die Erklärung annehmbar zu sein, daß das Radium als ein plysikalischer Reiz wirkt.

Erwägen wir die Radiumstrahlen in ihrer Wirkung auf Gewebe als physikalische (mechanische, Wärme, Licht, elektrische) oder chemische Reize, so werden wir uns leicht erklären können, wie einer verschiedenen Intensität der radioaktiven Wirkung resp. des Reizes Veränderungen verschiedenen Grades entsprechen. Wir halten uns für berechtigt, die von uns beobachteten Erscheinungen von Atrophie und Proliferation auf die verschiedene Intensität des Reizes und auf die verschiedene Natur der Zellen zurückzuführen. Jene entsprachen einem beginnenden und wenig intensiven Reize auf Zellev, diese erschienen auf denselben Zellen, aber später, oder auf Zellen eines Gewebes, das bestimmt war (Haarbulbus im Wechsel), zu verschwinden.

Diese Erklärung scheint uns am meisten logisch zu sein, um die Tatsachen, die wir bei unseren Experimenten beobachteten, zu interpretieren. Weil wir bei unseren Experimenten in der Lage waren, die verschiedensten Veränderungen von der Hyperplasie bis zur Atrophie zu beobachten, so glauben wir, dieselbe Interpretation auf die verschiedensten Gewebe anwenden zu können und die Wirkunng des Radiums im allgemeinen mit einem Reize auf die Vitalität und den Metabolismus der Zellen identifizieren zu können.

Die Affekte können sehr verschieden sein in Abhängigkeit von zwei Hauptfaktoren der Reaktion, einerseits die Sensibilität der Zellen, andernseits die Art und der Grad der radioaktiven Energie. Die Reparation der Veränderungen durch das Radium 
geschieht dort, wo es zur Gewebszerstörung kam, sehr langsam, aber mit einem Prozesse, gänzlich ähnlich dem normalen. Wir sahen die Regeneration der Epidermis durch Proliferation der alten; die Talgdrüsen bildeten sich wieder durch Differenzierung der Epithelfortsätze für die Reproduktion der Haare; letztere entstanden durch Regeneration aus den Resten des alten Haares (Reste der Bulbus und der Epithelscheide) oder durch Neubildung, je nach dem embryonalen Prozesse, aus Fortsätzen der neugebildeten Epidermis.

Wichtig ist die Tatsache, daß die Papillenelemente des Haares zähe widerstanden, indem sie auch nach dem Haarausfalle übrig blieben und daß aus den Resten der alten Papille sich größtenteils die Papille des neuen Haares bildete.

\section{Literatur.}

1. A b be. Referat in Deutsche med. Woch. 1906. p. 1508.

2. A polant. Deutsche med. Woch. 1904. Nr. 13.

3. - Ibidem. 1904. Nr. 31.

4. Blauel. Beiträge zur klin. Chirurgie. 1905. Bd. XLV. Ref. im Zentralbl. f. allg. Pathol. u. pathol. Anat. 1905. p. 358.

5. Bohn. Comptes rendus de l'Academie des Sciences. 1903. T. CXXXVI. p. 1012.

6. - Ibidem. 1903. T. CXXXVI. p. 1085.

7. - Comptes rendus de la Societé de Biologie. 1903. p. 1442.

8. Braunstein. Therapie der Gegenwart. Sept. 1904.

9. Castiglioni.

10. Curie et Becquerel. Comptes rendus de l'Academie des Sciences. 1901. T. CXXXII. p. 1289.

11. Daniel. Radioactivité.

12. Danysz. Comptes rendus de l'Academie des Sciences. 1903. T. CXXXVI. p. 461.

13. Dean.

14. Ein horn. Zeitschrift f. Krebsforscbung. 1905.

15. Evgelken. Beiträge zur klin. Chir. 1904. Suppl.

16. ExMer. Wiener klin. Woch. 1903. p. 804.

17. - Ibidem. 1904. Nr. 4.

18. - Ibidem. 1904. Nr. 7.

19. Gie sel. Berichte der deutschen chem. Ges. T. XXXIII.

20. Gilmann et Baetjer. Zit. von Schaper in Deutsche med. Woch. 1904. Nr. 39-40.

21. Gold berg. Inaugural-Dissertation. St. Petersburg. 1904.

22. Halkin. Arch. f. Derm. u. Syph. 1903. Bd. LXV.

23. Heinecke. Münchener med. Wochenschrift. 1904. Nr. 31.

24. Hirs chell.

25. L o ${ }^{2}$ d on. Presse medicale. 1906. Nr. 4.

26. Matsuoka. Deutsche Zeitschr. f. Chir. 1908. Bd. XCII. H. 4-6. 
27. Neuberg. Zeitschr. f. Krebsforschung. Bd. If. p. 171.

28. Obersteiner. Referat im Zentralbl. f. allg. Pathol. a. pathol. Anat. 1906. p. 252.

29. O koda. Ibidem. 1900, p. 105.

30. Perthes. Zeitschr, t. Krebsforschung. Bd. I. p. 79 und Arch. f. klin. Chir. Bd. LXXI. p. 955 .

31. - Deutsebe med. Woebensehrift. 1904. Nr. 17-18.

32. Porter et White.

33. Poussef. Referat in Daniel Radioactivité.

1904. p. 313 .

34. Rehns et Salomon. Comptes rendus de la Societé de Biologie.

35. Rehns. Ibidem. 1905. p. 491.

36. Salomonsen et Dreyer. Comptes rendus de l'Academie de

Sciences. 1904. T. CXXXVIII. p. 1543.

37. schaper. Deutsche med. Woch. 1904. Nr. 39 u. 40.

38. Schmidt. Ibidera, 1905.

39. Scholtz. Ibidem. 1904. Nr. 3.

40. - Ibidem. 1904. Nr. 25.

41. So hwarz. Pfügers Archiv. 1903. Bd. C. p. 532.

42. - Wiener klin. Woch. 1903. Nr. 24.

43. Strassmann. Arch. f. Derm. u. Syph. 1904. Bd. IXXXI.

44. Thal er. Deutsche Zeitschr. f. Chir. Bd. LXXXIX. H, 4-6.

45 . Thies. Mitteilungen aus den Grenzgebieten der Medizin und Chirurgie. Bd. XIV. H. 5 .

46. Tizzoni e Bongioranni. Il Radio e la rabbia. Zanietelli, Bologna. 1907.

47. Veneziani. Zentralbl. f. Physiologie. 1904. Bd. XVIII.

48. Walk off. Zit. von Curie e Becquerel, l. c.

49. Werner. Zentralblatt für Chirurgie. 1904. Nr. 43.

50. - Deutsche med. Wochenschrift. 1905. Nr. 2.

51. - Beiträge zur klin. Chirurgie. 1906. Bd. LII. p. 51.

52. Werner und Hirschel. Deutsche med. Woch. 1904. Nr. 42.

53. Wi chmann. Ibidem. 1906. Nr. 13.

54. W i ck h a m. La Clinique. 1908. Nr. 10.

55. Wintrebert. Comptes rendus de la Societé de Biologie. 1906.

56. Wo o lg e m uth. Berliner klin. Woch. 1904. Nr. 26.

57. Z uelzer. Archiv für Protistenkunde. 1905. Bd. V. H. 3.

\section{Erklärung der Abbildungen auf Taf. V-VIIT.}

Fig. 1. Normale Haut einer Maus. Vergr. 80 Diam.

Fig. 2. Seit 3 Tagen bestrahlte Haut. Epidermisknopf und leichte Vermehrung der Körnerschicht. Vergr. 80 Diam.

Fig. 3. Seit 5 Tagen bestrahlte Haut. Merkliche Verdickung und Schichtung der Epidermis; zellige Infiltration der Cutis. Vergr. 80 Diam. Fig. 4. Exzentrische Bestrahlungszone in seit 26 Tagen bestrahlter Haut. Verdickung und Schichtung der Epidermis mit Hyperkeratose. Vergrößerung 80 Diam.

Fig. 5. Parazentrale Zone in seit 26 Tagen bestrahlter Haut, metaplastische Hyperplasie aller Gewebe. Vergr. 80 Diam.

Fig. 6. Idem. Hypertrophie der Epidermis mit Hypertrophie und cystischer Umbildung der Talgdrüsen. Idem.

Fig. 7. Zentrale Zone in seit 19 Tagen bestrahlter Haut. Übergang der Hypertrophie zur Atrophie der Epidermis in beträchtlicher Hyperkeratose; mäßige zellige Infiltration der Cutis. Idem.

Fig. 8. Tangentialer Schnitt durch eine Gruppe von Haaren im Wechsel. Vergr. 160 Diam. 
Fig. 9. Analoger Schnitt in seit 5 Tagen bestrahlter Haut; zellige Proliferation im Follikel des Haares; Verdickung der Papille und des Pedunkulus; außerdem zellige Infiltration der Cutis und Hyperplasie mit Hyperkeratose der Epidermis. Vergr. 160 Diam.

Fig. 10. Tangentialer Schnitt durch zwei vom Haare entleerten Haarscheiden in seit 19 Tagen bestrahlter Haut; außerdem Hyperkeratose mit Atrophie der Epidermis. Vergr. 160 Diam.

Fig. 11. Tangentialer Schnitt durch eine Gruppe von Haaren, die durch primäre epitheliale Atrophie der Epithelhüllen entblößt sind, in seit 19 Tagen bestrahlter Haut; Epidermis noch hypertrophisch nnd in Hyperkeratose; Cutis ziemlich infiltriert. Vergr. 160 Diam.

F ig. 12. Zentrale Zone in seit 11 Tagen bestrahlter Haut. Auffallend ein Haarfollikel nach dem Haarausfalle, in einen fibrocellulären Strang umgewandelt, mit sehr deutlichem, papillärem Knötchen an seinem unteren Ende; überdies Hyperkeratose und vollständige Atrophie der Epidermis; Infiltration der Cutis. Vergr. 160 Diam.

Fig. 13. Schnitt durch ein Geschwür in seit 14 Tagen bestrahlter Haut. Atrophie und totaler Abfall der Epidermis, entzündliche Exsudation an der Oberfläche und in der Cutis, die das ausgefallene Haar darstellt. Fibrozelluläre Stränge. Vergr. 80 Diam.

Fig. 14. Schnitt durch ein radiumdermatitisches Geschwür auf dem Heilungswege in seit 37 Tagen bestrahlter Haut. Mitten in der granulierten Cutis drei Knötchen, Reste alter Papillen des Haares. Vergr. $80 \mathrm{D}$. Fig. 15. Rezente Narbe nach Radiumdermatitis in seit 70 Tagen bestrahlter Haut. Kallöse Narbenepidermis mit Mamellonierungen an der unteren Fläche; in der Cutis einige kleinzellige Knötchen, Residuen alter Papillen. Vergr. 80 Diam.

Fig. 16. Radiumdermatitische Narbe in seit 90 Tagen bestrahlter Haut. Deutliche Digitationen und Verlängerungen an der tieferen Fläche der kallösen Epidermis; verschiedene fibröse Reste.

Fig. 17. Radiumdermatitische Narbe in seit 120 Tagen bestrablter Haut. Epidermis noch ziemlich verdickt; in der Cutis zahlreiche kleinzellige Knötchen, umgeben von fibrösen Bündeln. Vergr. 80 Diam.

Fig. 18. Alte Narbe in seit 10 Monaten bestrahlter Haut. Epidermis wenig verdickt und in Evolution, um zu normalen Verbältnissen zurücksukehren. In der Cutis eine mehrlappige isolierte Talgdrüse. Idem.

Fig. 19. Hantschnitt, seit 14 Tagen bestrablt, mit Epidermis in Hypertrophie und Hyperkeratose. In der Mitte der Figur der Schnitt einer hyperplastischen Talgdrüse mit Mitosen gegen den Drüsengrund; an beiden Seiten der Drüse zwei Haare, ihre epitheloide Hülle in fortgeschrittener Atrophie. Vergr. 160 Diam.

F j g. 20. Schnitt einer rezenten Narbe in seit 75 Tagen bestrahlter Haut. Aktiver Prozeß von epitheloider Neubildung. Epithelfortsätze; eine neugebildete Talgdrüse mit Fortsätzen. Vergr, 160 Diam.

Fig. 21 u. 22. $\mathrm{Zw}$ wei Hautschnitte an der Grenze zwischen dem Geschwüre in Bildung und der noch nicht alopezischen Partie.

Fig. 23. Tangentialer Schnitt eines Epithelfortsatzes zur Regeneration des Haares.

Fig. 24. Parazentrale Zone von seit 45 Tagen bestrahlter Haut.

160 Diam

Fig. 25. Narbenschnitt in seit 75 Tagen bestrahlter Haut. Vergr.

26. Tangentialer Schnitt durch einen fibrösen Strang. Idem.

27. Schnitt einer parazentralen Zone, seit 26 Tâgen bestrahlt. Idem.

Aus dem italienischen Manuskripte übersetzt von M.U.Dr. Costantino Curupi in Prag-Bagni di Telese. 


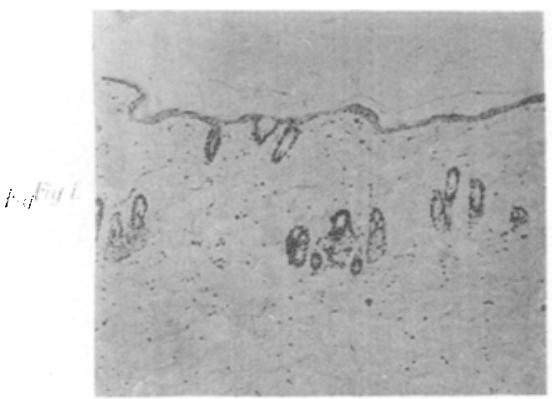

- Figf 2

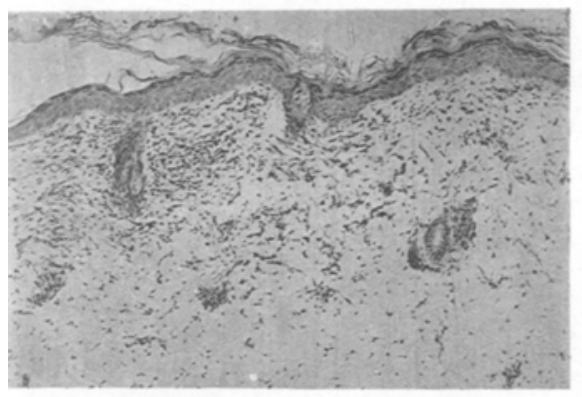

Fig.

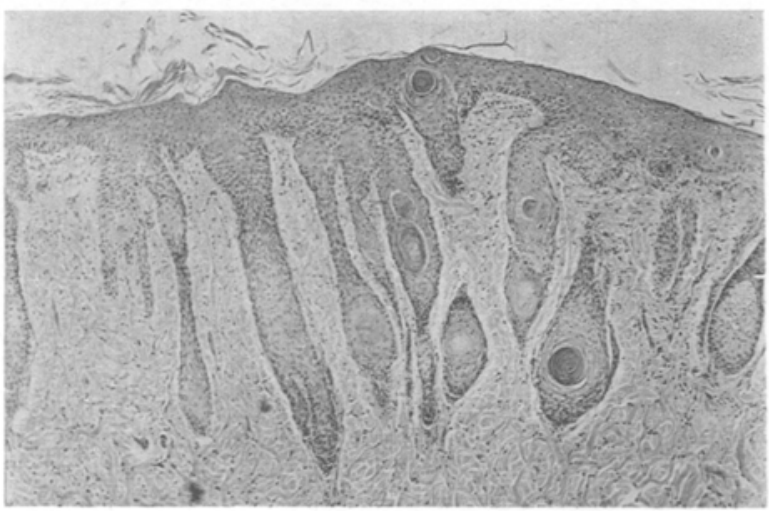

Fig?

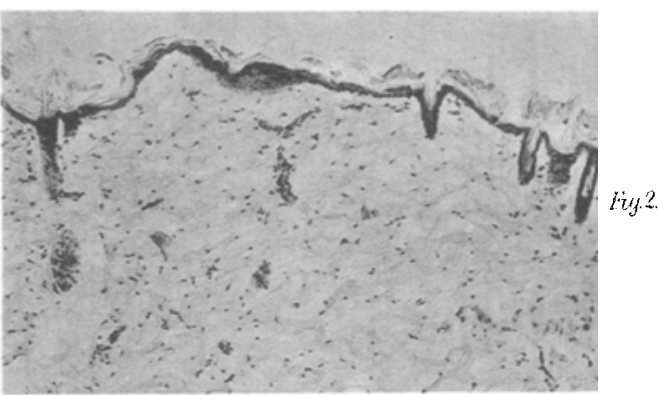

Fig. 4

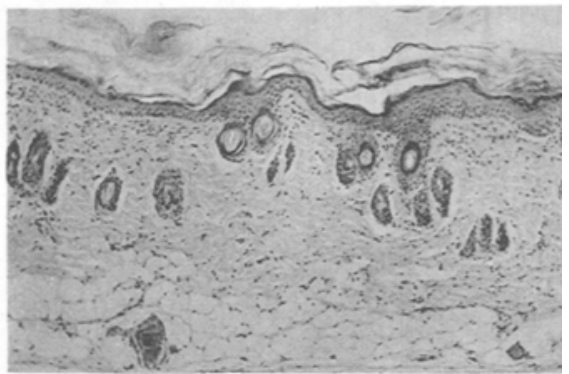

Fin 6.

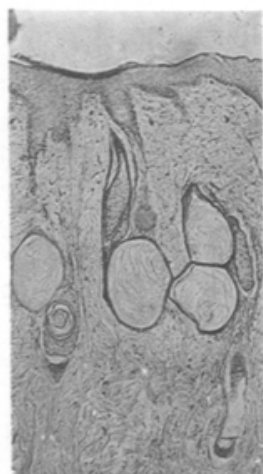

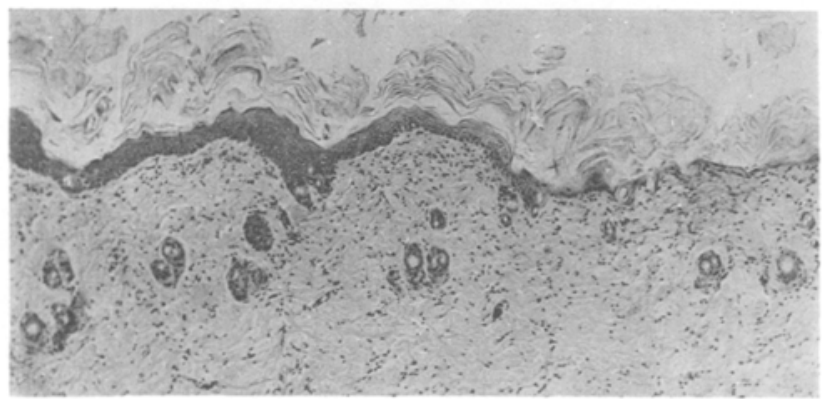



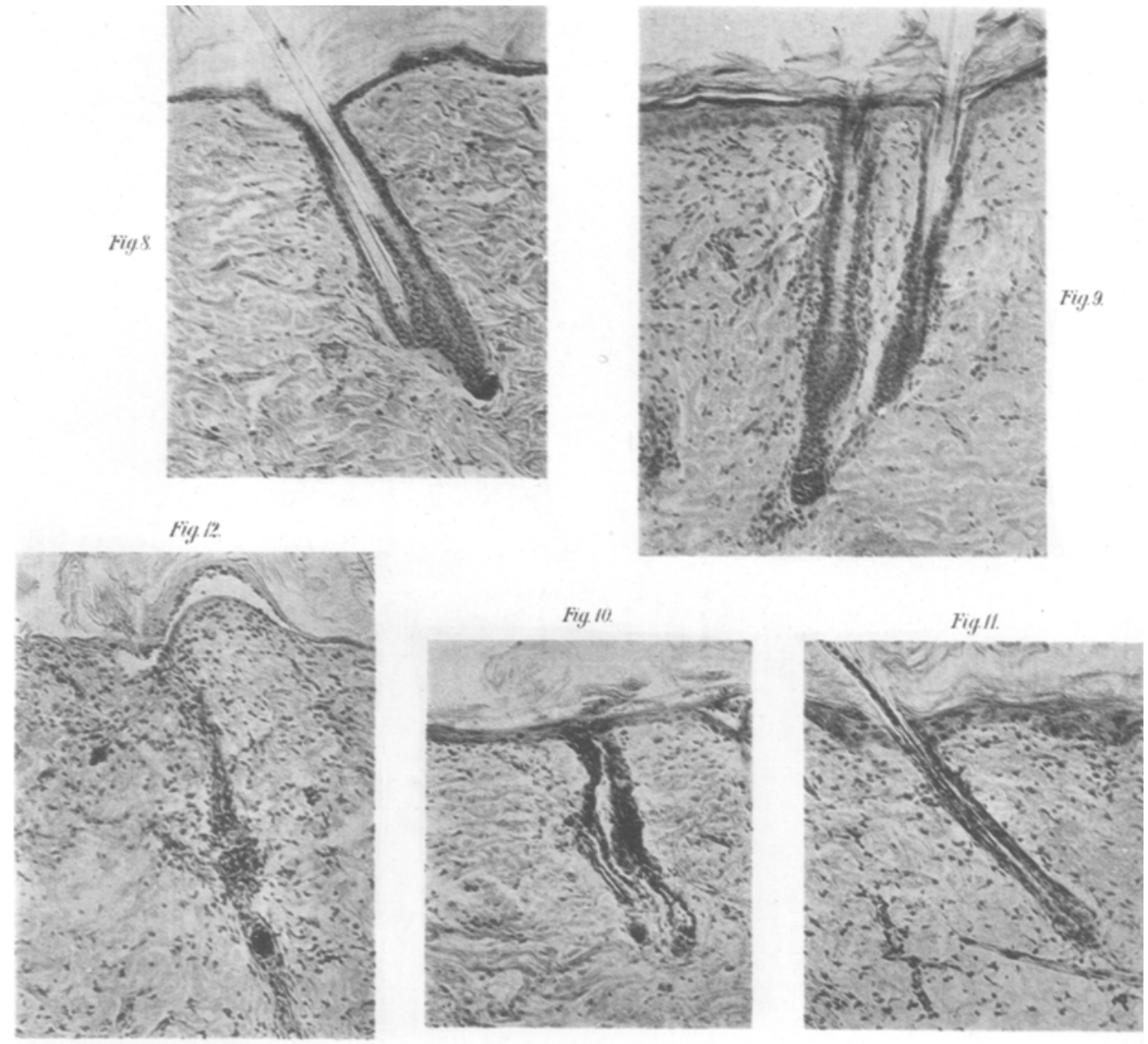

Fin B:

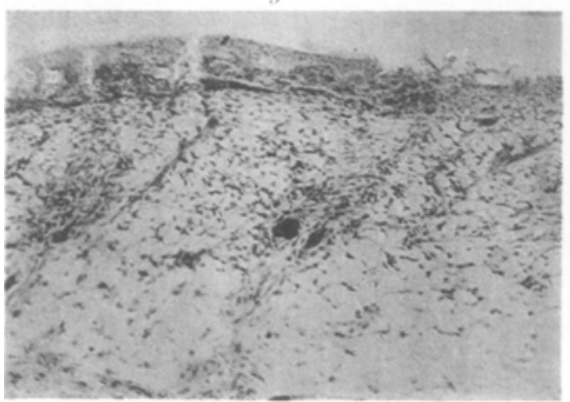

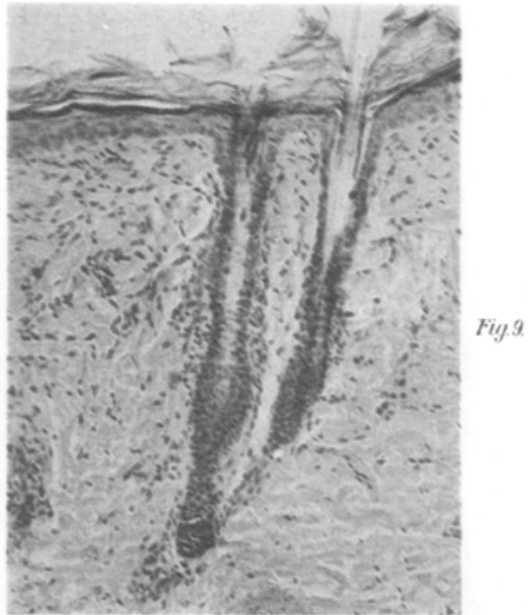

Fig. 9

\section{Fig./4}

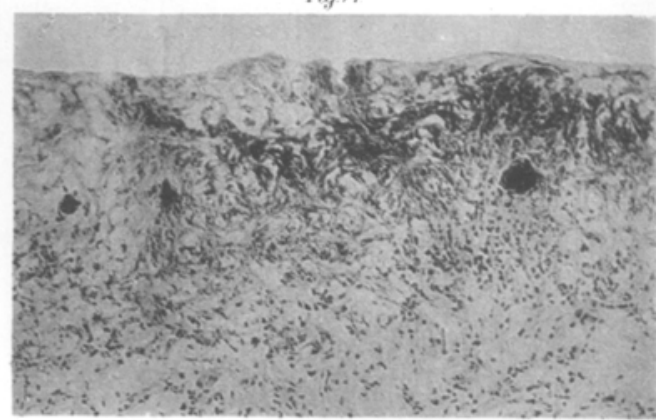





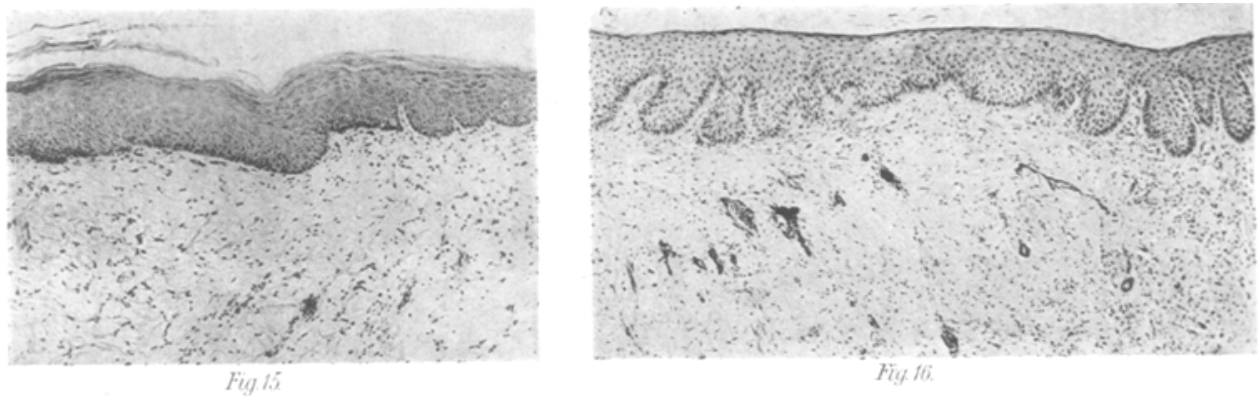

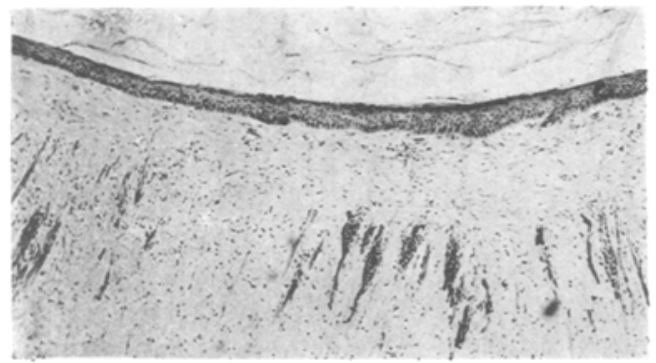

Fig. $f 7$

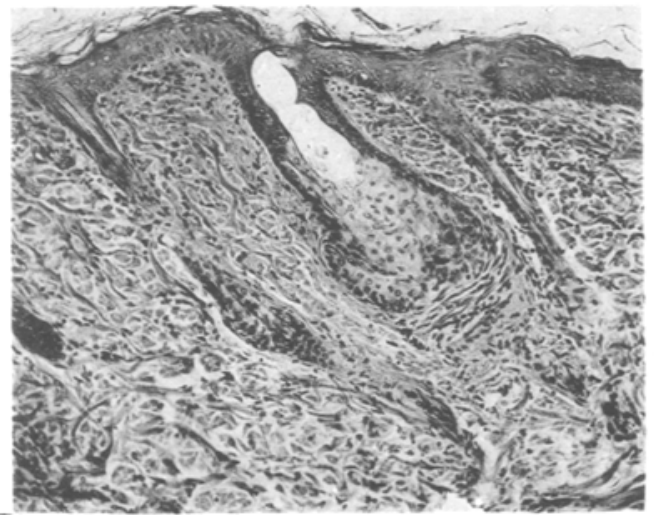

Fig. 19

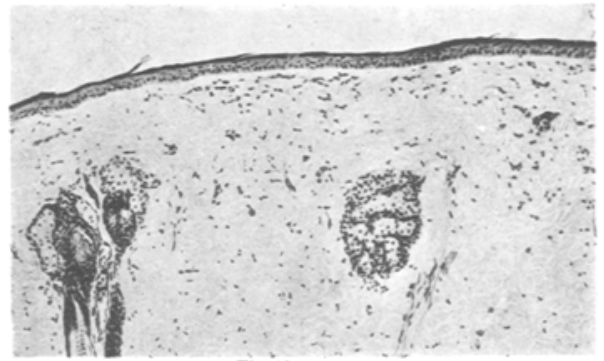

Fin. 18

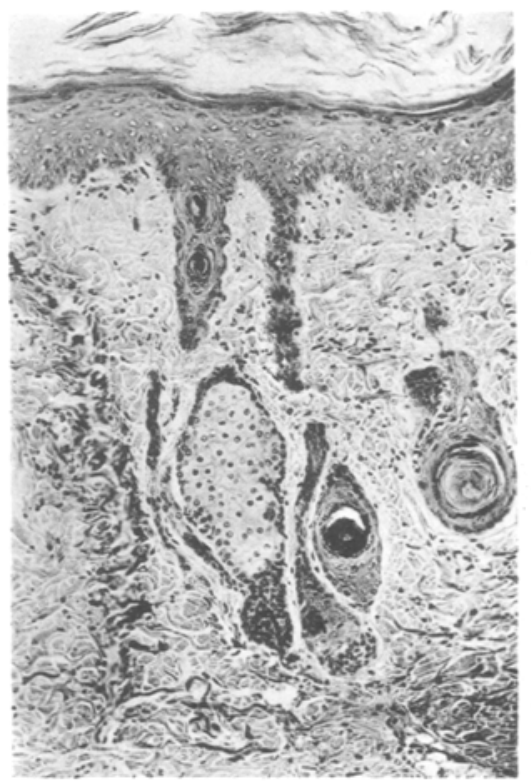

Guyot : Experimentelle Intersuchungen uiber die Wirkungen des Radiun auf das Hautgewebe. 


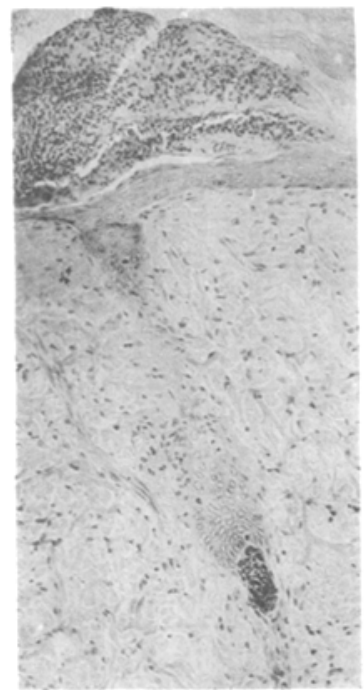

Fig 2

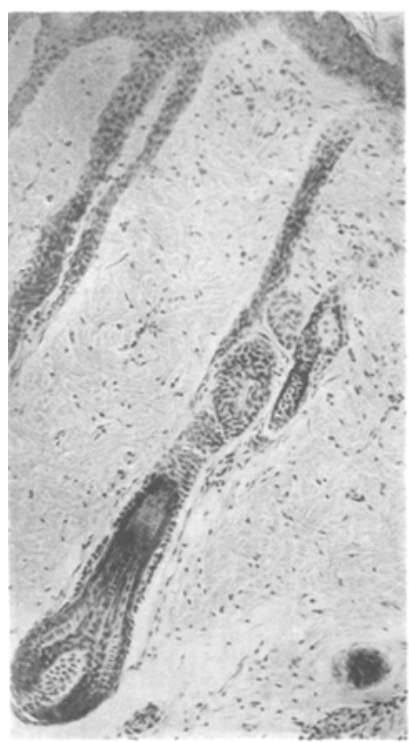

Fiy. 24

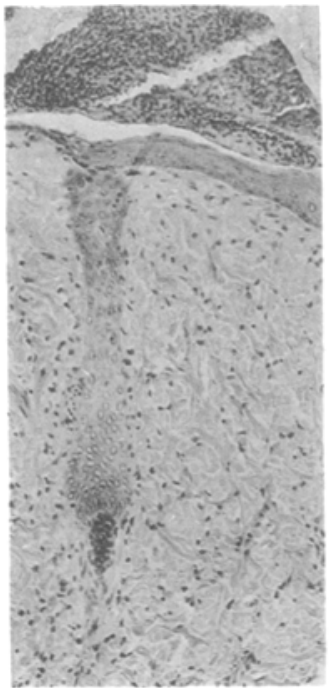

Fuy ??



Fïg. 23

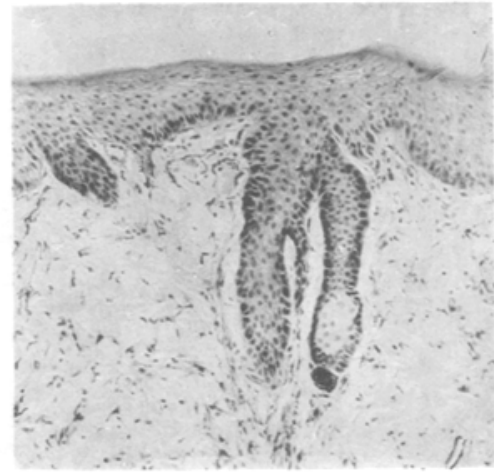

Fig. 25

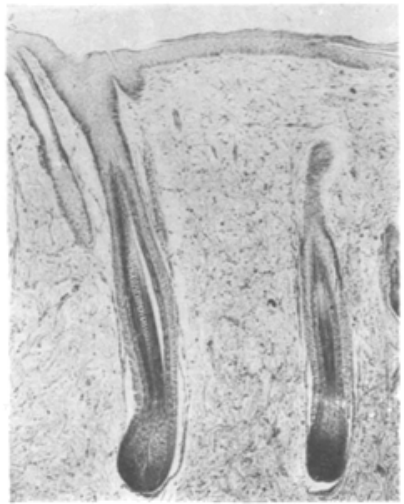

Fig 27

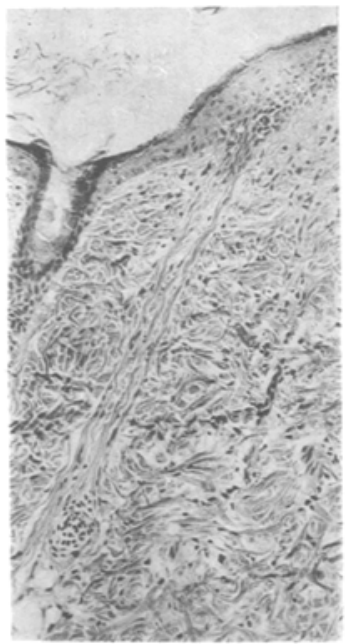

Fig $: 0$ 